\title{
Deep mantle melting, global water circulation and its implications for the stability of the ocean mass
}

\author{
Shun-ichiro Karato ${ }^{1 *}$ (D, Bijaya Karki ${ }^{2}$ and Jeffrey Park ${ }^{1}$
}

\begin{abstract}
Oceans on Earth are present as a result of dynamic equilibrium between degassing and regassing through the interaction with Earth's interior. We review mineral physics, geophysical, and geochemical studies related to the global water circulation and conclude that the water content has a peak in the mantle transition zone (MTZ) with a value of $0.1-1$ wt\% (with large regional variations). When water-rich MTZ materials are transported out of the MTZ, partial melting occurs. Vertical direction of melt migration is determined by the density contrast between the melts and coexisting minerals. Because a density change associated with a phase transformation occurs sharply for a solid but more gradually for a melt, melts formed above the phase transformation depth are generally heavier than solids, whereas melts formed below the transformation depth are lighter than solids. Consequently, hydrous melts formed either above or below the MTZ return to the MTZ, maintaining its high water content. However, the MTZ water content cannot increase without limit. The melt-solid density contrast above the $410 \mathrm{~km}$ depends on the temperature. In cooler regions, melting will occur only in the presence of very water-rich materials. Melts produced in these regions have high water content and hence can be buoyant above the $410 \mathrm{~km}$, removing water from the MTZ. Consequently, cooler regions of melting act as a water valve to maintain the water content of the MTZ near its threshold level ( 0.1-1.0 wt\%). Mass-balance considerations explain the observed near-constant sea-level despite large fluctuations over Earth history. Observations suggesting deep-mantle melting are reviewed including the presence of low-velocity anomalies just above and below the MTZ and geochemical evidence for hydrous melts formed in the MTZ. However, the interpretation of long-term sea-level change and the role of deep mantle melting in the global water circulation are non-unique and alternative models are reviewed. Possible future directions of studies on the global water circulation are proposed including geodynamic modeling, mineral physics and observational studies, and studies integrating results from different disciplines.
\end{abstract}

Keywords: Habitability, Ocean mass, Sea-level variations, Mantle transition zone, Water in the mantle, Deep mantle melting, Water valve

\section{Introduction}

The habitability conditions of a planet are often defined as the conditions in which its surface can maintain liquid water for billions of years (e.g., Kasting and Catling 2003; Kopparapu et al. 2013; Langmuir and Broecker

\footnotetext{
* Correspondence: shun-ichiro.karato@yale.edu

'Department of Earth and Planetary Sciences, Yale University, New Haven, CT 06520, USA

Full list of author information is available at the end of the article
}

2012). When the habitability conditions are defined in this way, it is implicitly assumed that if these conditions are met, oceans will have covered some (but not all) parts of a planet for billions of years. However, this is not necessarily true because the ocean mass on Earthlike planets is controlled by the dynamic equilibrium between the removal of volatile components from Earth's interior (degassing) and the transport of volatiles back into Earth's interior (regassing) (e.g., Holland 2003;

\section{Springer Open}

(c) The Author(s). 2020 Open Access This article is licensed under a Creative Commons Attribution 4.0 International License, which permits use, sharing, adaptation, distribution and reproduction in any medium or format, as long as you give appropriate credit to the original author(s) and the source, provide a link to the Creative Commons licence, and indicate if changes were made. The images or other third party material in this article are included in the article's Creative Commons licence, unless indicated otherwise in a credit line to the material. If material is not included in the article's Creative Commons licence and your intended use is not permitted by statutory regulation or exceeds the permitted use, you will need to obtain permission directly from the copyright holder. To view a copy of this licence, visit http://creativecommons.org/licenses/by/4.0/. 
Rubey 1951). Depending on the balance between regassing and degassing, oceans may disappear, or the surface may flood extensively. If either of them (or both) occurs for sufficient time, it will be difficult for life to emerge and evolve (e.g., Kite and Ford 2018). Therefore, commonly assumed "habitable conditions" are the necessary, but not the sufficient conditions to develop the biosphere we live in.

Both regassing and degassing involve global watercirculation processes in Earth's interior. Most previous studies emphasize shallow-mantle processes, such as degassing at mid-ocean ridges and regassing at subduction zones (Crowley et al. 2011; Franck and Bounama 2001; Karlsen et al. 2019; Korenaga 2011; Korenaga et al. 2017; McGovern and Schubert 1989; Rüpke et al. 2006) or the competition between degassing at ocean ridges and serpentinization in the ocean floor (e.g., Cowan and Abbot 2014; Kite and Ford 2018). Processes below the mantle transition zone (MTZ; a layer between $\sim 410$ and $\sim 660 \mathrm{~km}$ depth) have been treated in a highly simplified fashion, with a few exceptions (Bercovici and Karato 2003; Karato 2012; Karato et al. 2006) where the role of melting above the MTZ on global chemical circulation was emphasized. Observational evidence for deepmantle melting and water transport has been reported (e.g., Kuritani et al. 2011; Li et al. 2020; Liu et al. 2016, 2018; Schmandt et al. 2014; Tao et al. 2018; Tauzin et al. 2010; Yang and Faccenda 2020; Zhao and Ohtani 2009).

Nakagawa et al. (2015) is an important exception where they emphasized the separation of subducted oceanic crust into the MTZ. However, the degree to which oceanic crust carries water to the MTZ is unclear, nor did they explain the stability of water within the MTZ. The relationship between MTZ water content and the ocean-mass was not discussed in other studies.

In this paper, we review various observations to show the importance of the MTZ in the global water circulation. Motivated by seismic evidence of partial melting above and below the MTZ, we propose a new model in which partial melting around the MTZ buffers its water content, and hence (indirectly) stabilizes the ocean mass. However, given large uncertainties in the interpretation of various observations such as the sea-level change, we will also review alternative models.

\section{Water in Earth's mantle: Importance of the mantle transition zone}

\subsection{Water-storage capacity in mantle minerals}

Figure 1 illustrates regions that may play an important role in the global water circulation. Due to mantle convection and resultant partial melting and melt transfer, water may circulate deep into the mantle and return through Earth's surface into the oceans. For each region, we also estimate the water-storage capacity based on experimental results (e.g., Bolfan-Casanova 2005; Fu et al. 2019; Inoue et al. 2016; Inoue et al. 2010; Litasov et al. 2003; Peslier et al. 2017) (Fig. 2). The total water-storage capacity of the mantle is about $10 \times$ the present-day ocean mass. Particularly remarkable is the high waterstorage capacity of the MTZ, roughly 6x Earth's ocean mass. The potential size of the MTZ water reservoir draws attention to its possible influence on surface-

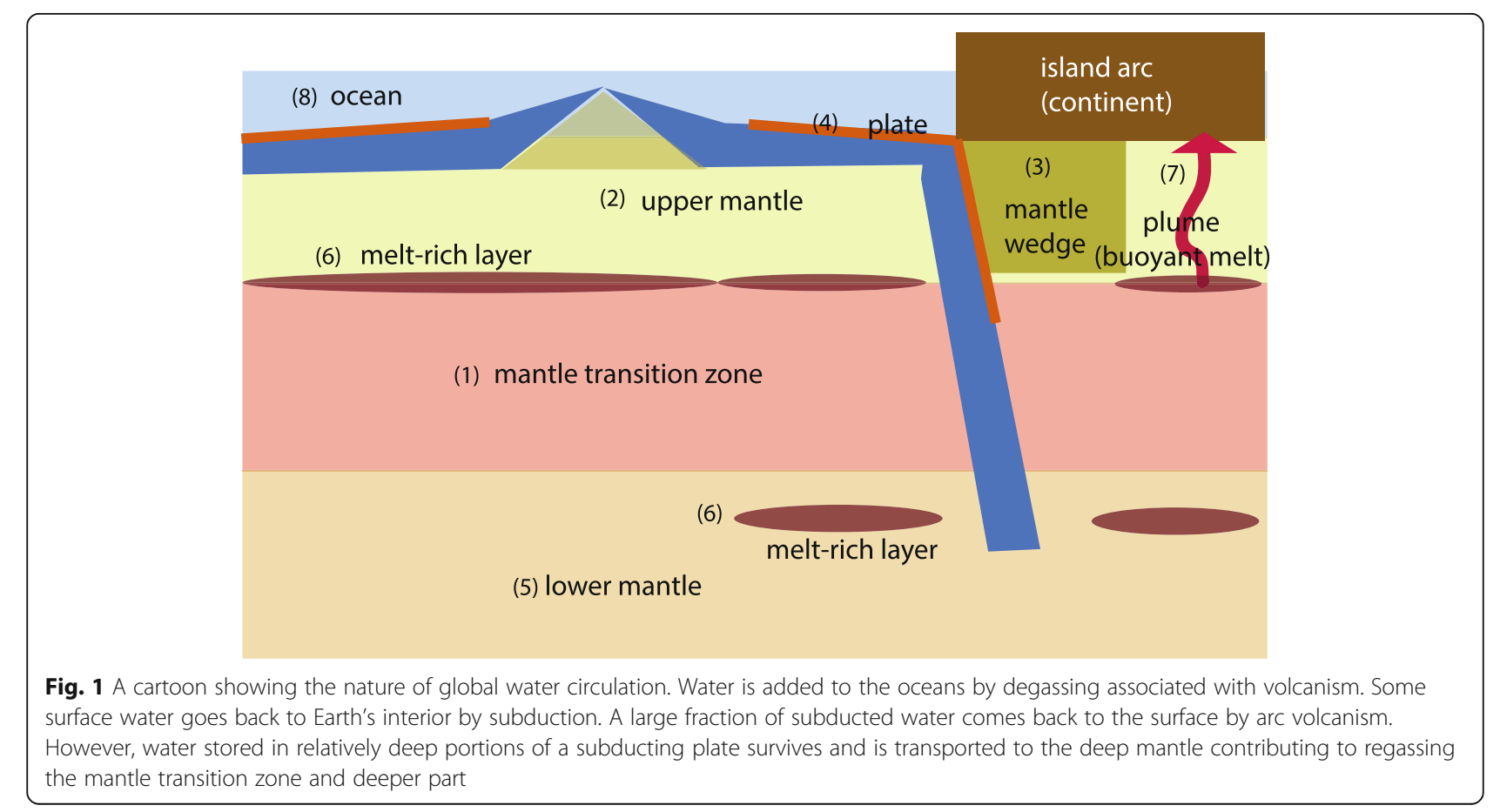




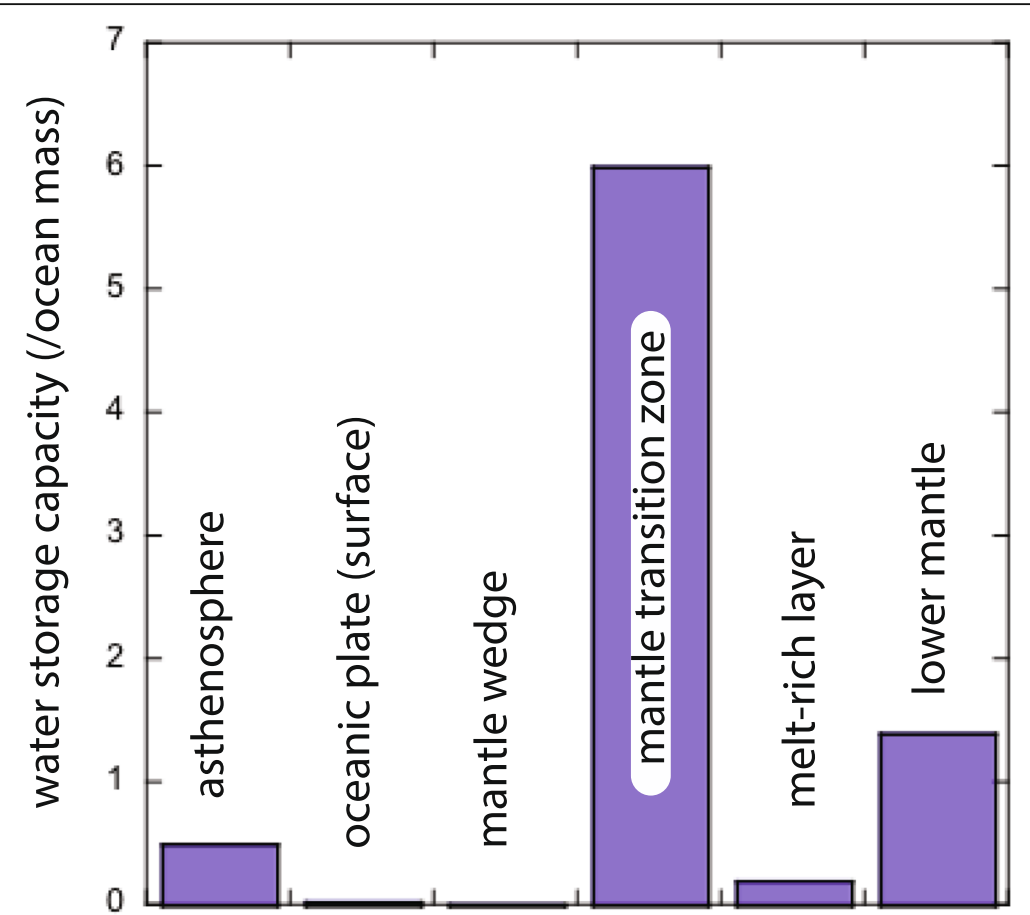

Fig. 2 The water storage capacity in several regions of the mantle. Note a large water storage capacity in the mantle transition zone. For the data source and uncertainties, see Table 1

ocean mass, complementing familiar shallow-mantle reservoirs, such as the asthenosphere and subduction-zone mantle wedges.

However, high water-storage capacity in the MTZ minerals does not guarantee high MTZ water-content. Water diffusion is inefficient for large-scale material transport: over $\sim 100 \mathrm{Myr}$, the diffusion distance of hydrogen is $\sim 1 \mathrm{~km}$ (Karato 2006). Consequently, large regions of Earth's interior can be dry, regardless of the water-storage capacity. Large-scale advection of volatilebearing materials is required to hydrate Earth's interior to near its storage capacity, and a dynamic equilibrium is required to maintain hydration over geological history. In particular, melting and the resultant melt-solid separation can effectively transport water (volatiles) for long distances. Efficient transport of water from Earth's surface into its interior could be catastrophic for life, if planetary water fills the MTZ to its capacity, with no mechanism to escape draining the oceans dry. Therefore, we must consider mechanisms for removing MTZ water as well as adding it. The actual water distribution in Earth provides key clues as to the processes of global water circulation.

Richard et al. (2002) modeled numerically the distribution of water, during mantle convection, where the depth dependence of water solubility (water storage capacity) was assumed including a peak in the MTZ. However, they only considered diffusional transport of water,

Table 1 Mass and the water storage capacity (the maximum water content that can be dissolved in minerals (or melts) in each region)

\begin{tabular}{|c|c|c|c|c|c|c|}
\hline & MTZ & $\mathrm{UM}^{\mathbf{b}}$ & Oceanic plate $^{c}$ & Mantle wedge $^{d}$ & $\mathrm{MRL}^{\mathrm{e}}$ & LM \\
\hline Mass $\left(10^{23} \mathrm{~kg}\right)$ & 4 & 5 & 0.1 & 0.1 & 0.8 & 20 \\
\hline Water storage capacity $\left(10^{21} \mathrm{~kg}\right)$ & $8(6)^{a}$ & $0.7(0.5)^{\mathrm{a}}$ & $0.05(0.03)^{\mathrm{a}}$ & $0.01(0.007)^{\mathrm{a}}$ & $0.4(0.3)^{a}$ & $2^{f}(1.4)^{a}$ \\
\hline
\end{tabular}

MTZ Mantle transition zone, UM Upper mantle, MRL Melt-rich layer, LM Lower mantle

Plumes containing buoyant water-rich melt are not included in this Table since their volume is unknown

${ }^{a}$ The numbers in the parenthesis are relative to the ocean mass $\left(=1.4 \times 10^{21} \mathrm{~kg}\right)$

'Typical upper mantle (asthenosphere) "plumes" containing water-rich buoyant melt are not included

${ }^{\mathrm{C} H y d r a t e d}$ portion of oceanic plate (5 km, $1 \mathrm{wt} \%$ water). The main part of the oceanic lithosphere (plate) is essentially dry (less than $0.01 \mathrm{wt} \%$ (Peslier et al. 2017)).

Upon excess cracking, this term will increase above the normal value listed in this table (e.g., Cai et al. 2018; Faccenda et al. 2009; Garth and Rietbrock 2014).

dMantle wedge is assumed to have $300 \mathrm{~km}$ depth and $200 \mathrm{~km}$ from the trench

${ }^{\mathrm{e}} \mathrm{MRL}$ above $410 \mathrm{~km}$ is assumed to be $1 \mathrm{~km}$ thick, and MRL at $\sim 750 \mathrm{~km}$ is assumed to be $50 \mathrm{~km}$ thick but occupies $\sim 10 \%$ of area, and the water content is assumed to be $0.5 \mathrm{wt} \%$ ( $5 \mathrm{wt} \%$ melt with $10 \mathrm{wt} \%$ water)

fThe water solubility in the lower mantle minerals is not well constrained. We used a value of 0.1 wt \% based on (Fu et al. 2019) (this is likely an over-estimate if we consider a likely pressure effect) 
and not advection. Their simulations showed no peak in water content within the MTZ, i.e., a dry MTZ. We show in this paper that Earth's distribution of water is determined by the large-scale mass transport associated with partial melting and subsequent melt-solid separation. A dry MTZ is a natural consequence of a model without these large-scale processes. The actual water distribution provides clues to the history of partial melting and melt-solid separation, i.e., chemical evolution of Earth.

\subsection{Water distribution in Earth's mantle}

The most direct way to estimate the water content of Earth's interior would be to measure the water content of mantle samples (for a review, see Peslier et al. 2017). However, the interpretation of these measurements is not straightforward because it is unclear how the water of a mantle sample is modified during its transport to the surface (e.g., Demouchy and Bolfan-Casanova 2016; Karato 2006). Regions from which mantle samples can be collected are limited. Most samples originate from < $200 \mathrm{~km}$ depth. Occasionally, samples from deeper regions have been identified from diamond inclusions (e.g., Nestola and Smyth 2016; Pearson et al. 2014; Tschauner et al. 2018), but it is not clear if these samples represent typical water content of the deep mantle.

Although indirect, the mid-ocean-ridge basalt (MORB) provides a better estimate of the water content of the asthenosphere. MORB is formed via 10\% partial melting of the asthenosphere materials at a global scale with near-homogeneous composition. Knowing that a majority of water in the original rock partitions into the melt upon partial melting, we can estimate the water content of the asthenosphere from the known water content of MORB ( 0.1\%; Dixon et al. 2002; Ito et al. 1983) to be $\sim 0.01 \mathrm{wt} \%$. Although less precise, we can estimate water content in the deeper mantle from ocean-island-basalt (OIB) that is formed from rocks that rise from the MTZ or the lower mantle. OIB shows a wider range of composition than does MORB, including water content, but they invariably show higher levels of water and other incompatible elements. These observations suggest that the deep mantle contains higher water content than the asthenosphere but water content in the deep mantle is likely more heterogeneous than in the asthenosphere.

Support for water-rich deep mantle is provided by recent discoveries of water-rich inclusions in diamonds of deep mantle origin. For example, Pearson et al. (2014) reported water-rich small $(\sim 50 \mu \mathrm{m})$ inclusions in diamond. The water content is close to the solubility limit $(\sim 1.5 \mathrm{wt} \%)$. A report of ice VII inclusions in diamonds that rose from the deep mantle through the MTZ argues for at least some water-rich regions at these depths (Tschauner et al. 2018). However, it is not known if such samples are representative of either the MTZ or deeper regions, making water-content estimates of the MTZ and deeper regions difficult.

In contrast to a geological approach, a geophysical approach provides constraints on the water (hydrogen) distribution in a more regional to global scale (Fei et al. 2017; Houser 2016; Karato 2011; Li et al. 2013; Suetsugu et al. 2006; Wang et al. 2019a). However, geophysical inference is not straightforward, and a broad range of water content, from nearly zero (Houser 2016) to nearly saturated (Fei et al. 2017), has been reported for Earth's mantle. The studies that report these two extreme water contents have technical ambiguities such as the insensitivity of seismic wave velocities to water content that undermine the validity of their conclusions (for details, see Supplementary Material). In the following, we assume that the MTZ contains a substantially larger amount of water $(0.1-1 \mathrm{wt} \%)$ than the asthenosphere ( $0.01 \mathrm{wt} \%)$ based on the studies on electrical conductivity (Karato 2011) and on the seismological observations (Li et al. 2013; Suetsugu et al. 2006; Wang et al. 2019a). We note that these estimates have large uncertainties, and it is likely that the water content in the MTZ is heterogeneous (Karato 2011; Wang et al. 2019b; Zhu et al. 2013).

In contrast, there are few constraints on the water content of the lower mantle. The agreement of electrical conductivity of dry bridgmanite with the geophysically estimated electrical conductivity of the shallow lower mantle (Xu et al. 1998) suggests a dry lower mantle, but both experimental and geophysical studies on electrical conductivity in the lower mantle are highly preliminary. There are no experimental studies on the influence of hydrogen on electrical conductivity in lower-mantle minerals.

\section{Partial melting across the mantle transition zone}

\subsection{Melting across the mantle transition zone}

Melting below mid-ocean ridges occurs because materials are brought up to shallow regions adiabatically and cross the solidus that increases more steeply with depth. Water helps melting below the mid-ocean ridges (e.g., Hirth and Kohlstedt 1996; Plank and Langmuir 1992), but the presence of water is not essential. As a result, mid-ocean ridge basaltic magma contains only a small amount of water $(\sim 0.1 \mathrm{wt} \%)$.

In contrast, melting in the middle mantle, above and below the MTZ, cannot occur without the help of water or other volatile elements. Without volatiles, the solidus $(\sim 2200-2300 \mathrm{~K})$ would be substantially higher than any plausible geotherm ( $1800 \mathrm{~K})$ (e.g., Andrault et al. 2011; Katsura et al. 2010; Ohtani 1987)). However, when water (and/or carbon dioxide) is added, the solidus temperature drops substantially, and partial melting 
becomes possible for a typical geotherm (Hirschmann et al. 2009; Kawamoto 2004; Litasov et al. 2013). The solidus water content defines the minimum water content for partial melting to occur. The melt formed by partial melting under hydrous conditions contains a large amount of water.

When water-rich transition-zone materials are transported to either above or below it, partial melting likely occurs because material assemblages outside of the MTZ have substantially smaller water-storage capacity than those inside the MTZ (Bolfan-Casanova et al. 2006; Inoue et al. 2010). For melting above the $410 \mathrm{~km}$, the threshold water content in the MTZ material is $\sim 0.05$ wt $\%$ for a typical temperature of $\sim 1800 \mathrm{~K}$ (e.g., Hirschmann et al. 2009; Karato et al. 2006). The water solubility in the lower mantle minerals is less well constrained. However, the available data show that the water solubility in the lower mantle minerals is less than or similar to that in the upper mantle minerals just above the $410 \mathrm{~km}$ (e.g., Fu et al. 2019; Inoue et al. 2010). Consequently, the threshold water content for partial melting just below the $660 \mathrm{~km}$ is likely $0.1 \mathrm{wt} \%$ or less.

Both temperature and water content in or around the MTZ are likely heterogeneous (Wang et al. 2019b; Zhu et al. 2013). The MTZ near a subduction zone likely has lower temperatures where stagnant slabs are present (Fukao et al. 2001). Consequently, the melt composition and hence density likely depend on where melting occurs. For example, where temperature is $1500 \mathrm{~K}(\sim 300$ $\mathrm{K}$ less than the temperature in the warm regions), then the critical water content for partial melting will be $\sim 0.1$ wt\% (Supplementary Material).

When partial melting occurs, a majority of water goes to the melt, and the residual solids will be depleted of water. When the melt density differs from the solid density and if the melt is inter-connected as suggested by the experimental studies (Panero et al. 2015; Yoshino et al. 2007), melt-solid segregation occurs by gravityinduced compaction as well as by the flow caused by the lateral pressure gradient (Leahy and Bercovici 2007; Ribe 1985a). Consequently, regional-scale $(\sim 100 \mathrm{~km}$ or more) re-distribution of water will result.

\subsection{Evidence of partial melting around the mantle transition zone}

The presence of low-velocity bodies in Earth's deep interior is often attributed to the presence of melt. However, the validity of this interpretation is unclear because partial melting can explain seismologically observed lowvelocity regions only when (i) the melt fraction is large (a few \%) and/or when (ii) melt completely wets grainboundaries (see, e.g., Mizutani and Kanamori 1964; Spetzler and Anderson 1968; Stocker and Gordon 1975; Takei 2002). Both of these factors differ markedly between above and below the MTZ. Just above the 410 $\mathrm{km}$ discontinuity, an experimental study showed that melt completely wets olivine grain-boundaries (Yoshino et al. 2007). Consequently, even for a small amount of melt (say $0.1 \%$ ), seismic wave velocity should be reduced substantially (a few \% or more) in regions just above the $410 \mathrm{~km}$. In contrast, in the lower mantle, the available data suggests that melt does not completely wet the grain-boundaries (dihedral angle of $\sim 30^{\circ}$ ) (Panero et al. 2015). Therefore in order to cause seismologically observable low-velocity regions below the $660 \mathrm{~km}$, there must be a melt-rich layer (MRL) containing a few \% of melt with a thickness comparable to or greater than the wavelength of seismic waves.

Under the influence of gravity, melt tends to be squeezed out if the melt density differs from the density of the surrounding solids. As a consequence, significant amounts of melt will exist only in a thin layer whose thickness is called the "compaction length" (Karato et al. 2006; McKenzie 1985; Ribe 1985b). During compaction, permeable flow of melt occurs only if the surrounding solids deform plastically. When there is a general background flow, the thickness of an MRL will also depend on the background flow velocity. Let us consider a case of one-dimensional (vertical) flow by mantle convection in which light (heavy) melt is produced at a boundary at $\sim 750 \mathrm{~km}$ (at $\sim 410 \mathrm{~km})$ where melt will accumulate. We denote these layers LVL-750 and LVL-410. In such a case, the thickness of an MRL is given by (Karato et al. 2006; Ribe 1985b).

$$
H=\sqrt{\frac{U_{o} \eta_{S}}{|\Delta \rho| g}}
$$

where $U_{o}$ is the velocity of background flow, $\eta_{S}$ is the viscosity of solid matrix, $g$ is acceleration due to gravity, and $\Delta \rho$ is density contrast between melt and surrounding solids.

Figure 3 shows a plot of $H$ as a function of $U_{o}$ and $\eta_{S}$. The compaction length depends strongly on the solid viscosity $\left(\eta_{S}\right)$ and the velocity of background vertical motion $\left(U_{o}\right)$. Both parameters differ substantially for MRL above and below the MTZ. For the up-welling flow that produces melt above $410 \mathrm{~km}$, the background velocity is $\sim 1 \mathrm{~mm} /$ year (Bercovici and Karato 2003) and the solid viscosity is $\sim 10^{18}-10^{20} \mathrm{~Pa}$ s. Note that the average viscosity at $\sim 400 \mathrm{~km}$ depth is $\sim 10^{20} \mathrm{~Pa} \mathrm{~s}$ (Peltier 1998), but viscosity could be substantially lower near $410 \mathrm{~km}$ due to the presence of melt. For a plausible range of parameters, $H$ above the $410 \mathrm{~km}$ is $\sim 1 \mathrm{~km}$ or less and consequently, it will not be visible seismologically if a large melt fraction were the cause for the low velocity. Low 


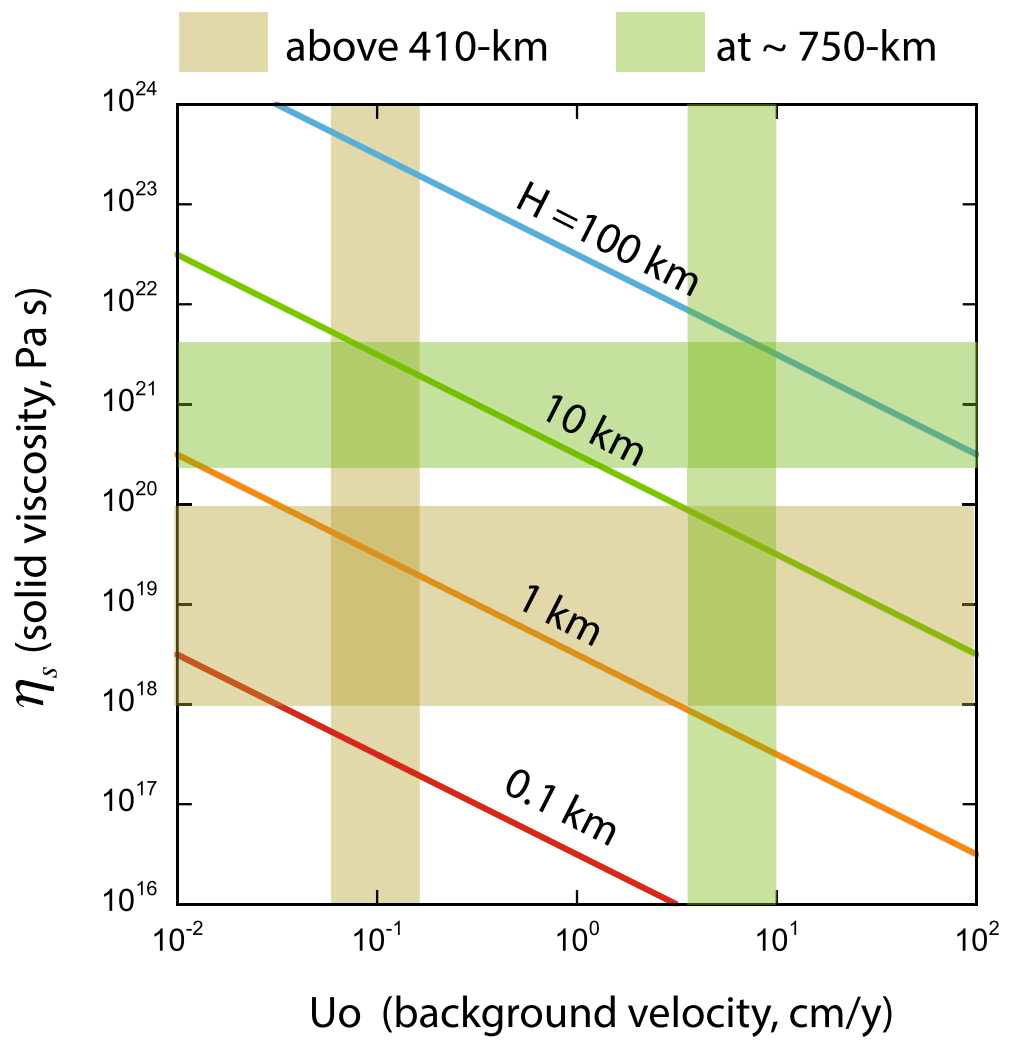

Fig. 3 The thickness of a melt-rich layer. When melt is formed in a region of vertical flow (with the velocity Uo), and when melt flows to the opposite direction of the background flow as in the most case of partial melting across the MTZ, a melt-rich layer is formed near the region

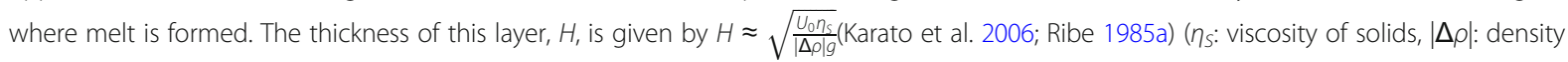
difference between the melt and the solids $\left(\sim 100 \mathrm{~kg} / \mathrm{m}^{3}\right), g:$ acceleration due to gravity). Both $U_{0}$ and $\eta_{s}$ are markedly different between the melt-rich layer above and below the MTZ leading to largely different values of $H$

velocities observed above the $410 \mathrm{~km}$ discontinuity are most likely due to the fact that melt completely wets grain-boundaries (Karato 2014a).

In contrast, in a layer at $\sim 750 \mathrm{~km}(\mathrm{LVL}-750)$, the downwelling velocity of materials is similar to the velocity of a subducting plate $(\sim 3-10 \mathrm{~cm} /$ year $)$, that is, much higher than the up-welling velocity near $\sim 410 \mathrm{~km}$. The solid viscosity is also higher, on the order of $10^{21} \mathrm{~Pa} \mathrm{~s}$ (Peltier 1998) (could be reduced somewhat by the presence of melt). A combination of these two factors predicts the thickness of the MRL to be $\sim 20-50 \mathrm{~km}$. This would be seismologically detectable even though melt may not completely wet grain-boundaries. Note, however, that melt accumulation to explain the LVL-750 will occur only if melt is lighter than co-existing solids. If melt is denser than coexisting solids, it will drain and accumulate only at a deeper depth at which melting stops. For heavy melts, the melt content near $750 \mathrm{~km}$ will be small and not much velocity reduction will occur. Therefore, the presence of a thick MRL caused by the accumulation of a buoyant melt is a plausible explanation of the LVL-750 (for more detail, see Section 6).

\subsection{Melt density}

Most melts are lighter than coexisting rocks in the shallow Earth and this is why magmas ascend to the surface to form a volcano. However, melt buoyancy is more complicated in the deep interior of Earth. Melts are more compressible than solids (Jing and Karato 2011) and melt density approaches or exceeds that of coexisting solids at high pressures (Stolper et al. 1981). Consequently, the density contrast between a melt and co-existing solids is delicately controlled by the composition and the compressibility of melt and solid under high-pressure conditions.

Figure 4a shows the density of three melts up to 60 GPa based on the first-principle calculations as well as from experiments (Karki et al. 2018; Sakamaki 2017; Sanloup et al. 2013; for the technical details of melt density calculation, see Supplementary Material). The results show that the melt is always lighter below the solidtransformation depth but the melt is heavier than the solid, in most cases, above the solid-transformation depth. This is due to the fact that the structure of solids (e.g., a change in the coordination number of $\mathrm{Si}-\mathrm{O}$ ) changes 


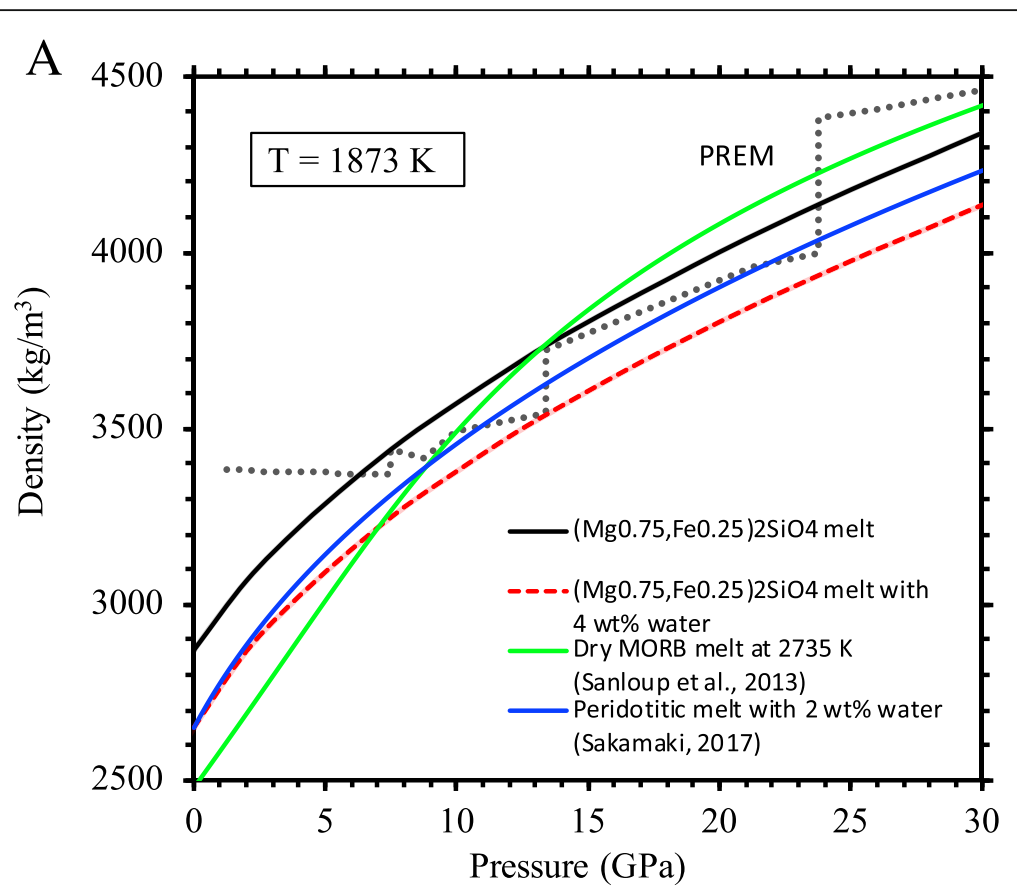

$\mathrm{B}$

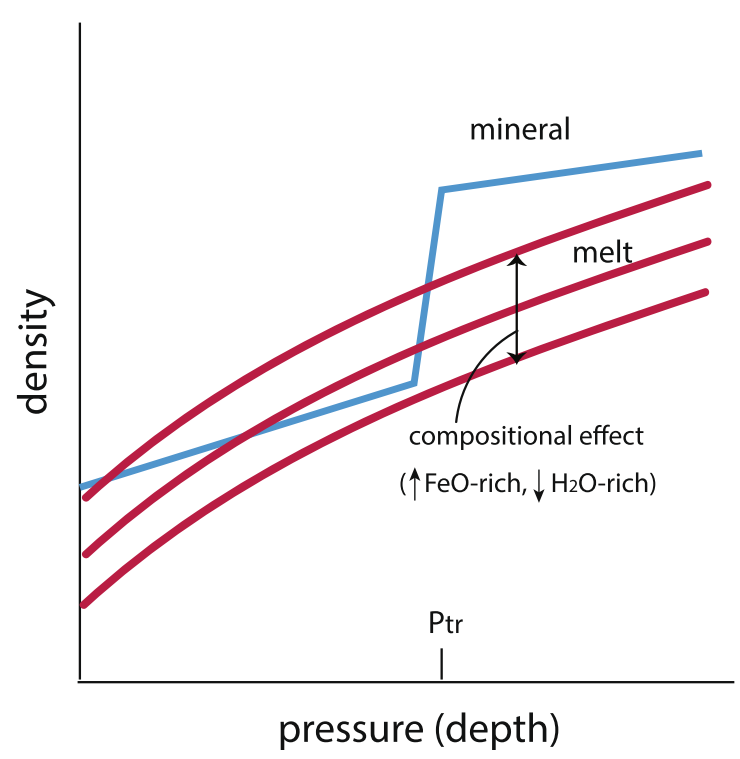

Fig. 4 The melt density across the mantle transition zone. a Melt density compared with the density of co-existing solids. The broken line shows the solid density. Black and red curves are the melt density based on the first-principles calculations of dry and hydrous $\left(\mathrm{Mg}_{0.75}, \mathrm{Fe}_{0.25}\right)_{2} \mathrm{SiO} \mathrm{O}_{4}$ melts (with hatched regions showing the influence of different compositions). A green curve is the density of dry MORB determined by (Sanloup et al. 2013) and a blue curve is the density of hydrous peridotite melt determined by (Sakamaki 2017) from high-pressure experiments. The gray region shows the effects of a change in $\mathrm{FeO}$ content by $\pm 5 \%$, and the pink region shows the effects of water by \pm 2 wt.\%. $\mathbf{b}$ A schematic diagram showing how density of melt and solid changes across a phase transformation. Structural change in a solid is abrupt, but it is gradual in a melt. This leads to higher density of a melt than a solid above the transition pressure, but below the transition pressure, melt density tends to be lighter than the solid density

sharply at the solid phase transformation, whereas a similar structural change occurs more gradually for the melts. In melts structural change starts at a lower pressure than in solids and structural change develops gradually with pressure, completing at a pressure higher than the sharp crystalline phase change (Fig. 4b).

The melt-solid density contrast depends also on chemical composition. For plausible ranges of $\mathrm{FeO}$ and water 
content, the density of melt below the $660 \mathrm{~km}$ is mostly less than that of co-existing solids. This is caused by a large density jump in solids across the $660 \mathrm{~km}$. In contrast, the density trade-off is more delicate at $\sim 410$ $\mathrm{km}$-see calculations graphed in Fig. 5. Water content in the melt changes with the temperature at which melting occurs. At low temperatures, melting occurs only for high volatile content within the MTZ mineral assemblage, and the water content of the melt is large. Consequently, melts produced in the cooler regions, e.g., where stagnant slabs are present, will be buoyant whereas melts formed in the warmer regions will be heavy. The consequences of temperature on the density contrast will be examined in a later section where we propose a new model of global water circulation.

\section{Sea-level history}

An important clue on the history of ocean mass can be obtained from the sea-level history. Sea-level changes via a variety of mechanisms (e.g., Mitrovica et al. 2000; Wise 1972). For the time scale of $1000-10,000$ years, the largest contribution is ice-sheet formation/melting and resultant isostatic vertical crustal motion (e.g., Nakada and Lambeck 1987; Peltier 1998). The contribution of this process to the sea-level change is large, up to $\sim 200 \mathrm{~m}$. However, for time scales longer than 100 Myrs, the influence of ice sheet formation/melting cancels when averaged over time. Over these longer time scales, sea-level history is controlled by tectonic (geological) factors and/or changes in the ocean mass (e.g., Eriksson 1999; Korenaga 2007; Korenaga et al. 2017; Wise 1972)).

Figure 6 shows such results, i.e., the sea-level history during the Phanerozoic period (present to $\sim 540 \mathrm{Ma}$ ) (after Parai and Mukhopadhyay 2012). Although there are some differences in the reported sea-level history, the common and remarkable observation is that the sealevel fluctuates substantially on 10-100 Myr time scales ( 2 to $3 \mathrm{~m} / \mathrm{Myrs}$ ), yet it remains nearly constant (less than $\sim 0.5 \mathrm{~m} /$ Myrs) when averaged over the last $\sim 500$ Myrs. If the higher rate of change had persisted for a billion years, most oceans would have disappeared or the surface would have extensively flooded over $\sim 1$ Gyrs. However, despite large fluctuations, sea-level appears to recover and the average sea-level does not change so much.

Which part of the observed sea-level change reflects the ocean mass history and which part is caused by tectonic processes? If sea-level change were mostly by tectonic processes, then ocean mass would remain nearly constant. In contrast, if sea-level change is largely due to the change in the ocean mass, then one needs to explain how ocean mass can fluctuate a lot but remains nearly constant on average.

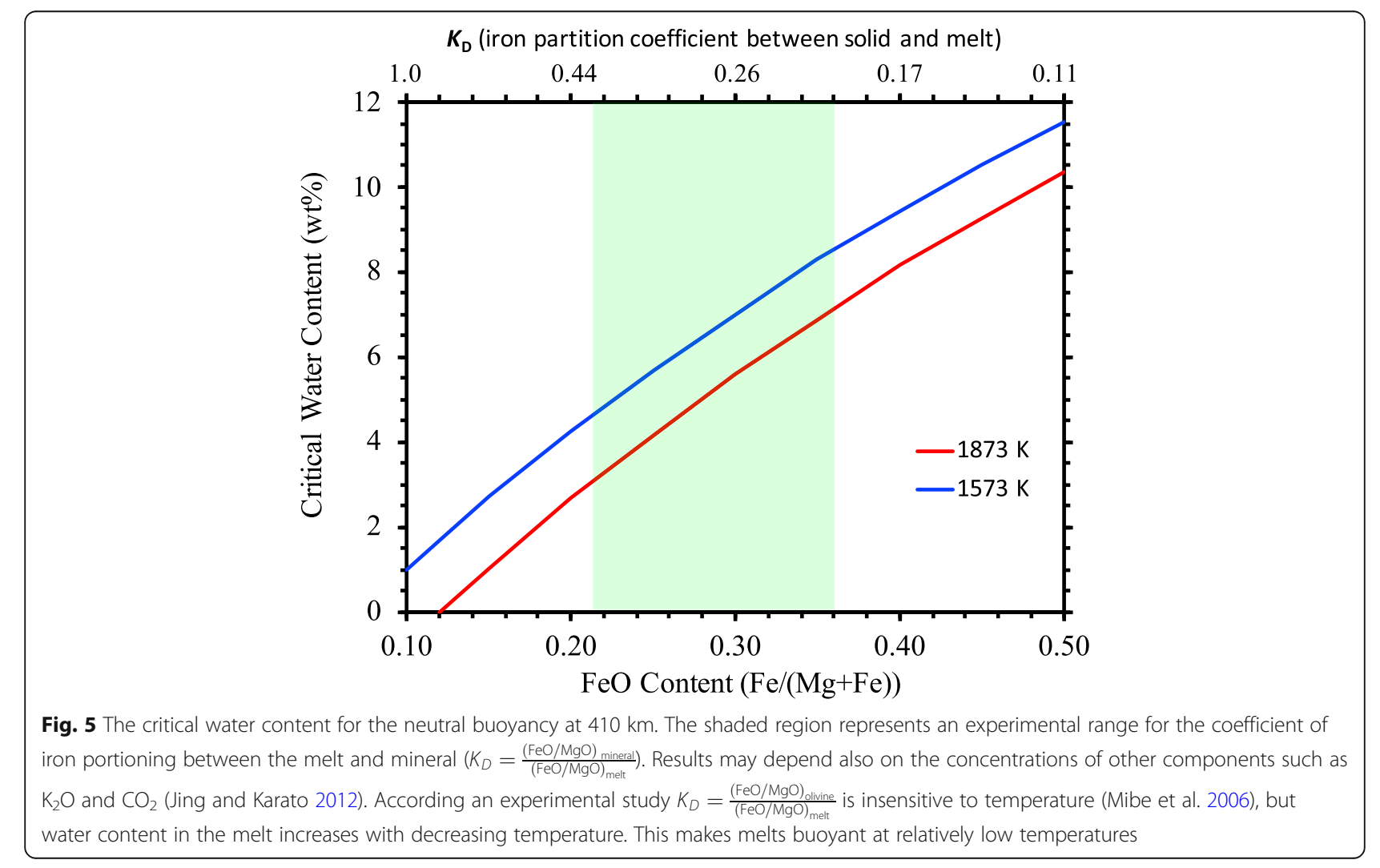



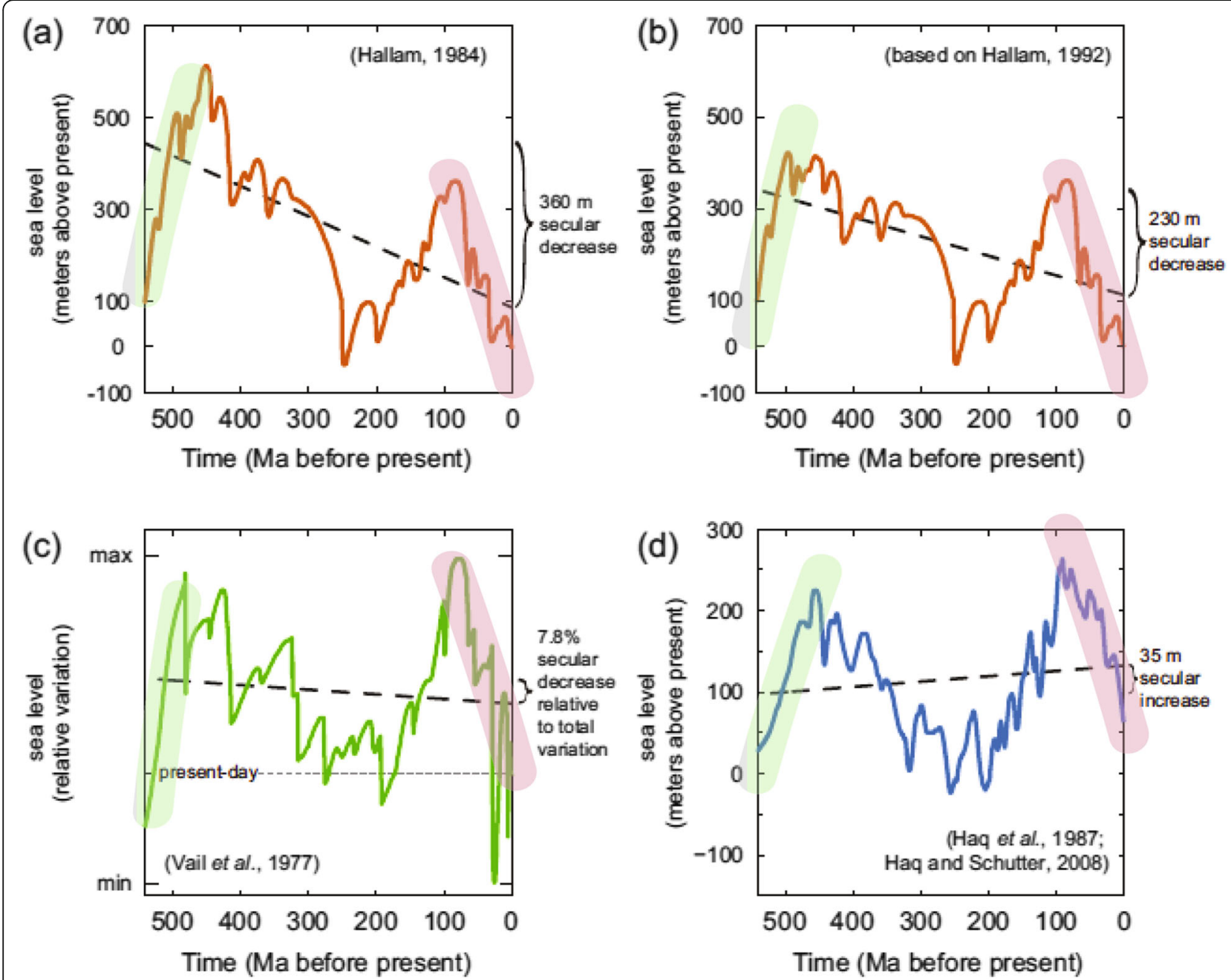

Fig. 6 Sea-level change during the Proterozoic (after Parai and Mukhopadhyay 2012). The sea-level variations show large fluctuations, yet an average sea-level changes only weakly with time (hatches are added by the present authors to emphasize the short-term fluctuations)

Figure 7 shows a cartoon illustrating the processes that determine the sea-level where $h$ is the sea-level measured at the coast, $\bar{z}$ is the mean depth of ocean $(3710 \mathrm{~m}$ at present), $f$ is the fraction of the surface covered by the continents, and $X$ is dynamic topography associated with the vertical stresses caused by mantle convection. The volume of oceans relates to these parameters as

$$
V(t)=[h(t)+X(t)-\bar{z}(t)] \cdot[1-f(t)] \cdot S
$$

where $S$ is the area of oceans.

Dynamic topography is the deviation of continental topography out of isostatic equilibrium, depending on material flows that are regional and time dependent. Gurnis (1993) invoked dynamic topography to explain the flooding of continents during the Phanerozoic Eon. This effect is sensitive to the viscosity $(\eta)$ of convecting material $(X \propto \eta)$ in the relevant region. For sea-level measurements, viscosity of the mantle below the continental margin is relevant, and the viscosity in the continental margins can vary a lot among different regions. Where subduction occurs, viscosity will be substantially lower than other regions, as suggested by Billen and Gurnis (2001). Gurnis (1993) used a standard one-dimensional viscosity-depth model, such as Hager and Clayton (1989), that does not have a low viscosity region in the wedge mantle. If regional low viscosity in the supraslab mantle wedge is included, the magnitude of dynamic topography will be substantially lower (Billen and Gurnis 2001). The influence of continental growth $(f(t))$ is not very large when we focus on the sea-level in the Phanerozoic where the continental growth is less than $\sim 10 \%$ (Korenaga 2018). Consequently, among various tectonic effects, the influence of variation of the mean depth of oceans $(\bar{z}(t))$ is likely most important. $V(t) \approx[h(t)-\bar{z}(t)] \cdot S$. 


\section{f}

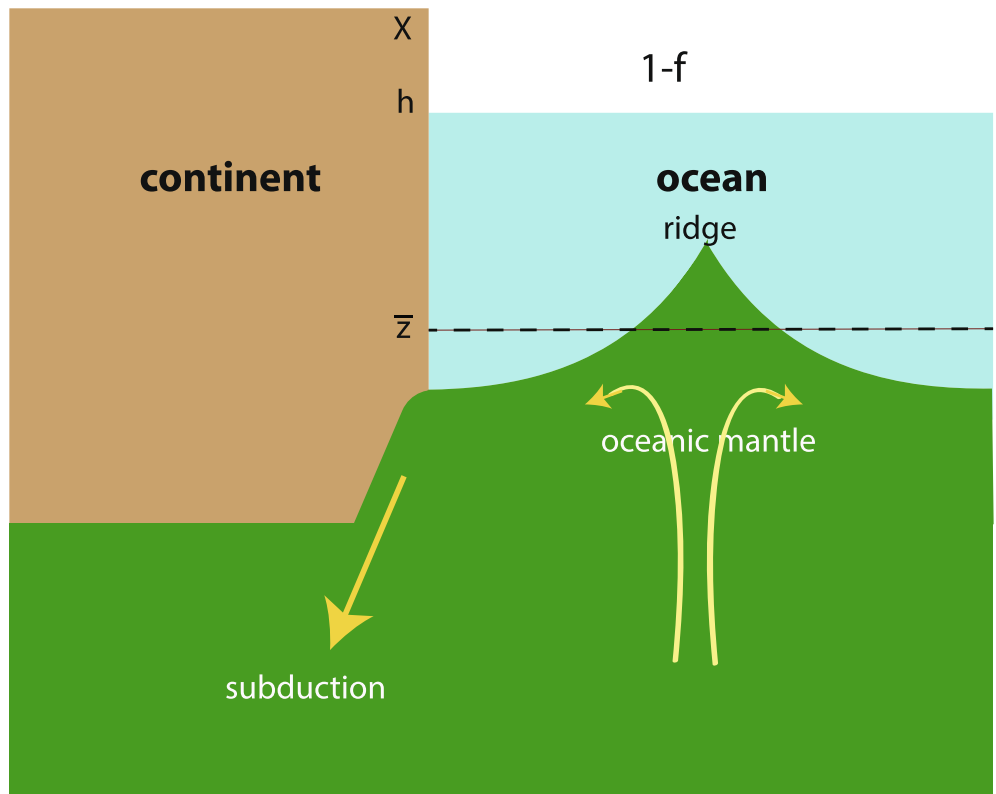

Fig. 7 A cartoon illustrating the factors affecting the sea-level (from Karato 2015). $h$ : the sea-level, $f$ : areal fraction of continents, $\bar{z}$ : the mean depth of the ocean that depends on the mean age of the ocean floor, $X$ : height of the continental margin that depends on the dynamic topography determined by the mantle flow

The depth of oceans depends on the age of ocean floor through isostatic equilibrium as $z=z_{0}+A \sqrt{t}$ (e.g., Parsons and Sclater 1977) in the half-space-cooling model, where $z_{o}$ is the ocean depth at a mid-ocean ridge where $t$ (age) is zero and $A$ is a constant $(A=330 \mathrm{~m} / \sqrt{M y})$. Therefore in order to have $\sim 300 \mathrm{~m}$ variation in sea-level for $\sim 100$ My time period, a change of the mean depth of $\sim 30 \%$ is needed. The variation in the mean depth of the ocean floor can be evaluated based on the data on the age-area distribution of the ocean floor (Parsons 1982) and the plausible models and observations of the temporal variation in ridge spreading rate and subduction rate (Korenaga 2007). Using this line of discussion, Korenaga (2007) concluded that changes in the heat flux since $200 \mathrm{Ma}$ are too small to explain a large variation in the sea-level (the change in the average age is a few \% or less, corresponding to the change in the average age of $\sim 5 \%$ or less). However, the estimate of the mean age of sea floor is complicated, and much larger variation has also been reported, e.g., by Müller et al. (2016). Karlsen et al. (2019) used this model and attribute a large fraction of observed sea-level change to the change in tectonic processes. Accepting these uncertainties, we will discuss models based on these two models of history of plate motions, i.e., models with small and strong influence of $\bar{z}(t)$.

Among the inferred sea-level changes in various time span, the sea-level change in the recent $\sim 100$ Myrs is best constrained. The sea-level has dropped rapidly in this period with a rate of $2-3 \mathrm{~m} / \mathrm{Myrs}$. If this were due to the change in the ocean mass, the rate of change in the ocean mass would be $\sim(1.0-1.5) \times 10^{18} \mathrm{~kg} / \mathrm{Myr}$. Garth and Rietbrock (2014) and Cai et al. (2018) reported seismological observations on the Kuril and Mariana trench respectively suggesting the deep hydration (to $20-40 \mathrm{~km}$ from the top of the subducting slab) of subducting plates. Deeply hydrated regions likely survive against dehydration caused by heating during subduction (e.g., Rüpke et al. 2004) and from these observations, they estimated a high regassing rate of $\sim 2$ $\times 10^{18} \mathrm{~kg} / \mathrm{Myr}$ that agrees with the rate of sea level drop during the last $\sim 100$ Myr. Although the estimate of regassing is highly uncertain, its order-of-magnitude supports the notion that some part of the recent sealevel change is due to the change in the ocean mass.

\section{Water circulation across the mantle transition zone: the role of deep mantle melting}

Let us now examine various models with the emphasis on how they can explain two notions summarized above: (i) the high water content of the MTZ, and (ii) the longterm stability of the average sea-level despite large fluctuations. Remembering the fact that the MTZ has the largest water-storage capacity and large water content, these two notions are linked by mass conservation. 


$$
M_{\mathrm{MTZ}} \frac{d X_{\mathrm{MTZ}}}{d t} \approx-\frac{d W_{\text {ocean }}}{d t}
$$

where $M_{\mathrm{MTZ}}$ is the mass of the MTZ, $X_{\mathrm{MTZ}}$ is the mass fraction of water in the MTZ, and $W_{\text {ocean }}$ is the mass of oceans. On time scales long enough for hydrated rock to subduct or ascend through the upper mantle, the evolution of MTZ water is directly related to the evolution of the ocean mass and hence sea-level history.

In the following, we will develop a simple conceptual model to explain a peak in water content of $0.1-1 \mathrm{wt} \%$ in the MTZ that also explains the negative feedback in the evolution of the ocean mass suggested by the observed sea-level history and compare our new model with others. In seeking a model to explain the observed sea-level history, we will focus on explaining why sealevel is nearly constant with large medium-term fluctuations. Since Earth's deep interior is a big water reservoir, it is likely that some process of negative feedback operates within it.

As outlined in Fig. 1, the processes of water transport are different between up-welling and down-welling regions, and hence water content in the MTZ is likely heterogeneous. However, to simplify the analysis, we will consider a model where only the average water content of the MTZ is considered.

$$
M_{\mathrm{MTZ}} \frac{d X_{\mathrm{MTZ}}}{d t}=\Gamma_{\mathrm{MTZ}}^{+}-\Gamma_{\mathrm{MTZ}}^{-}
$$

where $\Gamma_{\text {MTZ }}^{+,-}$is the regassing (or degassing) rate to (or from) the MTZ. In such a case, the model becomes onedimensional where a single parameter, $X_{\mathrm{MTZ}}$, represents the average water content of the MTZ. Such a simplification is justifiable if we consider the evolution of the ocean mass since mixing of mass in the ocean is quick. However, such a model does not provide any detailed prediction of the lateral variation in the water content in the MTZ.

Under this simplification, it is easy to show that if there is no melting, then the steady-state average water content in the MTZ will be given by (see Supplementary Material)

$$
\tilde{X}_{\mathrm{MTZ}}^{\text {no melting }}=\frac{1}{2}\left(X_{\text {up }}+X_{\text {down }}\right)
$$

where $X_{\text {up }}$ is water content in the upwelling regions $(\sim$ water content of the lower mantle) and $X_{\text {down }}$ is the average water content in materials in the down-welling regions just above the MTZ. Both $X_{\text {up }}$ and $X_{\text {down }}$ are small: $X_{\text {up }}$ is not well constrained but its upper limit is the water solubility in the lower mantle minerals $(0.01$ wt\% or less (Bolfan-Casanova et al. 2006; Inoue et al.
2010)) and $X_{\text {down }} \sim 0.01 \mathrm{wt} \%$ or less. Assuming a $5 \mathrm{~km}$ thick layer of $1 \mathrm{wt} \%$ water (oceanic crust) with a 500 $\mathrm{km}$-wide down-welling region, one would get $X_{\text {down }} \sim$ $0.01 \mathrm{wt} \%$. If one includes the influence of shallow dehydration, $X_{\text {down }}$ would be substantially less. Therefore, we conclude that without partial melting, the MTZ would be nearly dry $(<0.01 \mathrm{wt} \%)$. This agrees with the results of Richard et al. (2002).

Let us now consider a case where dehydration melting occurs both above and below the MTZ in material that advects out of it (Fig. 8). We first assume that all the melt formed above the $410 \mathrm{~km}$ is heavier than surrounding solids (this assumption will be relaxed later), and the melt formed below the $660-\mathrm{km}$ is lighter than the surrounding solids (Fig. 5). In such a case, the MTZ can maintain high water content since most of water is in the melts and melts return to the MTZ. The steady-state water content of the MTZ in this case can be calculated by solving the mass balance Eq. (4) with appropriate formulae for $\Gamma^{+,-}$(see Supplementary Material) as

$$
\tilde{X}_{\mathrm{MTZ}}^{\text {melting }}=\frac{\tilde{X}_{\mathrm{MTZ}}^{\text {no melting }}-\frac{U^{\prime}}{U} \frac{X_{S}}{X_{L}-X_{S}}}{1-\frac{U^{\prime}}{U} \frac{X_{L}}{X_{L}-X_{S}}} \approx \frac{\tilde{X}_{\mathrm{MTZ}}^{\text {no melting }}}{1-\frac{U^{\prime}}{U}} \geq \tilde{X}_{\mathrm{MTZ}}^{\text {no melting }}
$$

where $U$ is the velocity of general circulation (mantle convection) and $U^{\prime}$ is the velocity of entrainment $\left(U^{\prime}<\right.$ $U) ; X_{L, s}$ is the water content at the liquidus and the solidus respectively. This model predicts higher water content of the MTZ than that for a case of no melting, but evaluation of the steady-state water content is difficult because entrainment rate $\left(U^{\prime}\right)$ is not well constrained. If entrainment is very efficient $\left(\frac{U^{\prime}}{U} \rightarrow 1\right)$, then the water content becomes unbounded: all water would be eventually trapped in the MTZ, and oceans will shrink to negligible size.

This entrainment paradox arises from the assumption that all water partitions to the melts surrounding the MTZ and all the melts return to the MTZ. This paradox is mitigated because some of the original water remains in the residual solids, so that a small amount of water escapes from the MTZ. This escaped water defines the water content of the asthenosphere (Karato 2012). However, the amount of water escape by this process is small, and would only replenish Earth's ocean mass in $\sim 10$ Gyr (e.g., Parai and Mukhopadhyay 2012).

Is there any process by which water leaks from the MTZ more efficiently than a general slow leak from the hot region? Temperature in the MTZ is heterogeneous 

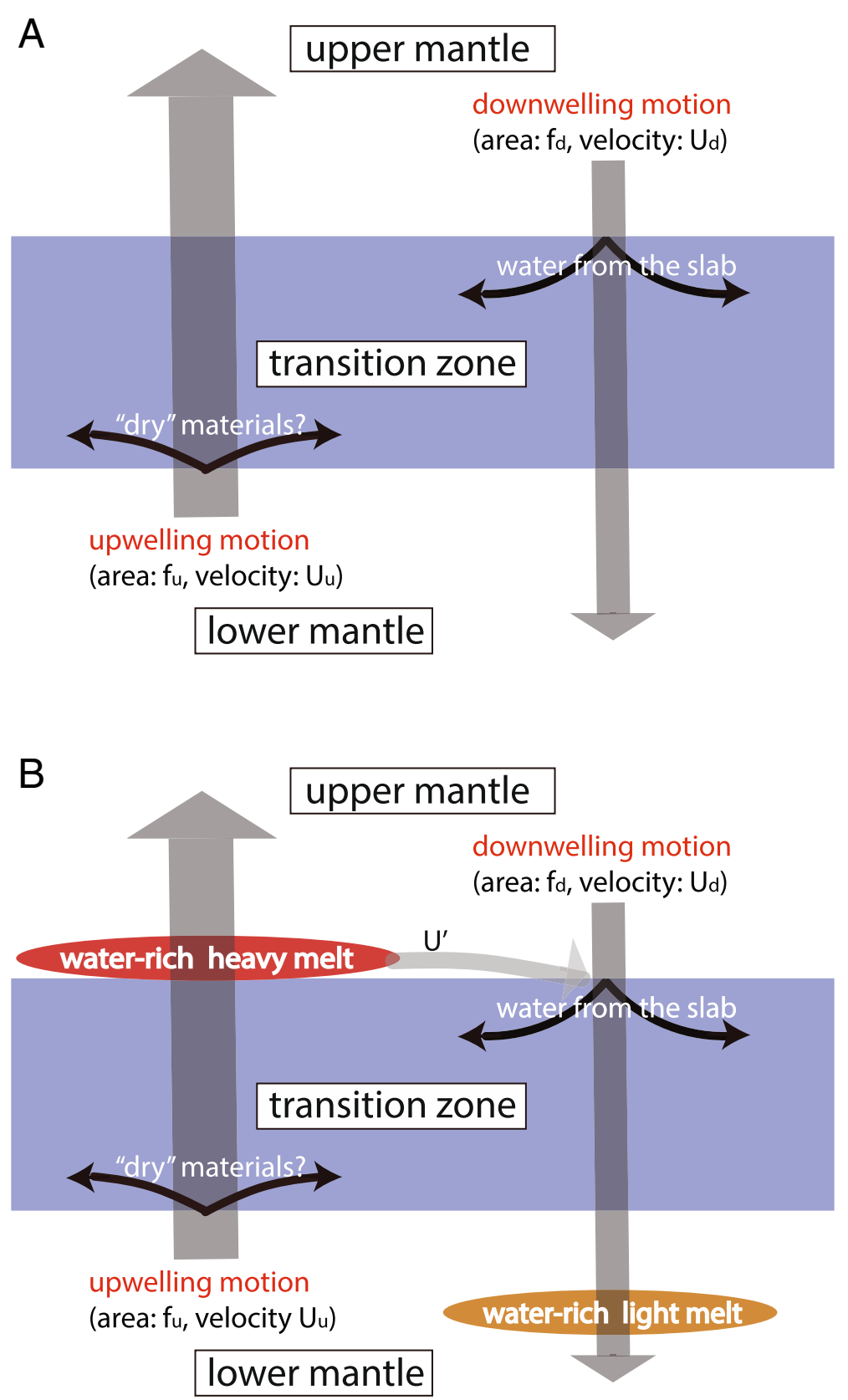

Fig. 8 A model of water transport across the mantle transition zone. a A model without melting $f_{u}$ : area fraction of upwelling, $f_{d}$ : area fraction of down-welling, $U_{u}$ : velocity of upwelling, $U_{d}$ : velocity of down-welling. From the mass conservation, $f_{u} U_{u}=f_{d} U_{d} \equiv \frac{1}{2} U$. b A model with melting. In this model, we assume that melts formed above the MTZ are heavy and the melts formed below the MTZ are light. $U^{\prime}$ the velocity of migration of the MRL materials from upwelling regions to the subduction zones (this depends on mantle viscosity and is fast only above $410 \mathrm{~km}$ )

(Figs. 9 and 10). Since cooler down-welling flow is concentrated in regions near the subduction zone, the majority of the MTZ is warm. However, there are cooler regions including the regions where stagnant slabs are present. In cooler regions, partial melting occurs only if the water content of materials is high $\left(X_{\mathrm{MTZ}}>X_{C 0}\right)$ and the water content in the melt is higher than the melt derived from warmer MTZ regions (in contrast to water,
$\mathrm{FeO}$ content in the melt $(\mathrm{FeO} / \mathrm{MgO}$ ratio of the melt) relative to that in mineral is insensitive to temperature (Mibe et al. 2006), so melt density (relative to the solid density) changes with temperature mainly through the temperature effect on the water content in the melt). With sufficient water content, the melt will be buoyant (Jing and Karato 2012) (see Fig. 5). Consequently. buoyant melt could be formed in cool regions. 


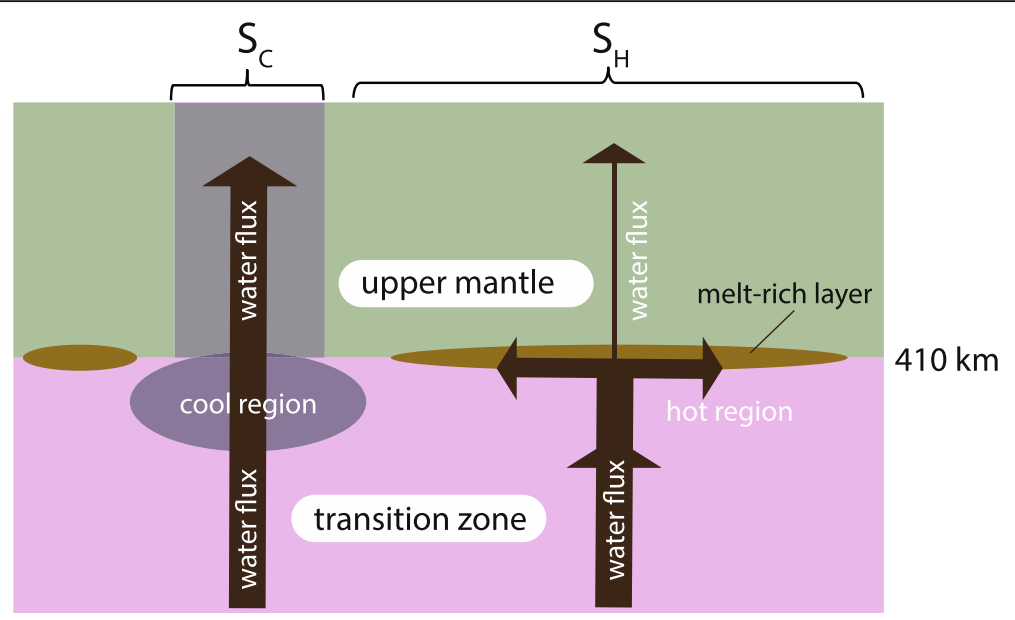

Fig. 9 Processes of water transport across the $410 \mathrm{~km}$ with heterogeneous temperature. In the hot region (area $S_{H}($ a majority of regions)), melts are dense and spread on the 410-km boundary and eventually be entrained into the transition zone (Bercovici and Karato 2003; Karato et al. 2006). Only a small amount of water is transported upward by the residual solids to define the composition of the asthenosphere (Karato 2012). In the cool region (area $S_{C}$ ), melt is buoyant and if there is enough amount of buoyant melt present (a case $X_{M T Z} \geq X_{C 2}$ (shown here)), substantial degassing from the MTZ will occur

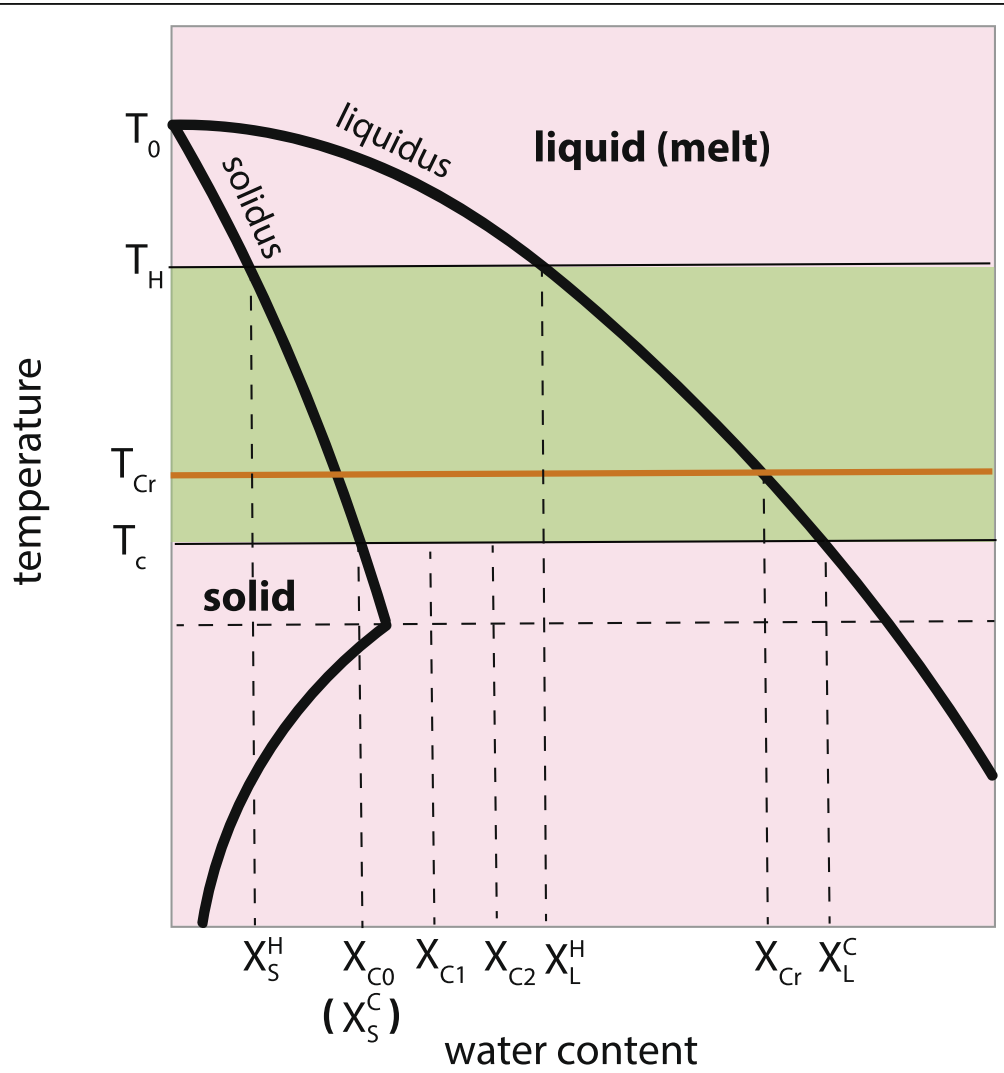

Fig. 10 A schematic phase diagram at $\sim 410 \mathrm{~km}$. A green region represents temperature distribution. $T_{H, C}$ is temperature in the hot $(H)$ or the cold $(C)$ regions respectively. $T_{C r}$ is temperature at which the melt has high enough water content and is buoyant. $X_{S}^{H, C}, X_{L}^{H, C}$ are the water content at the solidus and liquidus in the hot or the cold region respectively. $X_{C 1}$ is the minimum water content in the transition zone where the melt will ascend $(\sim 0.2 \%) . X_{C 2}$ is the water content above which hydrated materials above the MTZ are buoyant to form a plume $(\sim 1 \%$; 


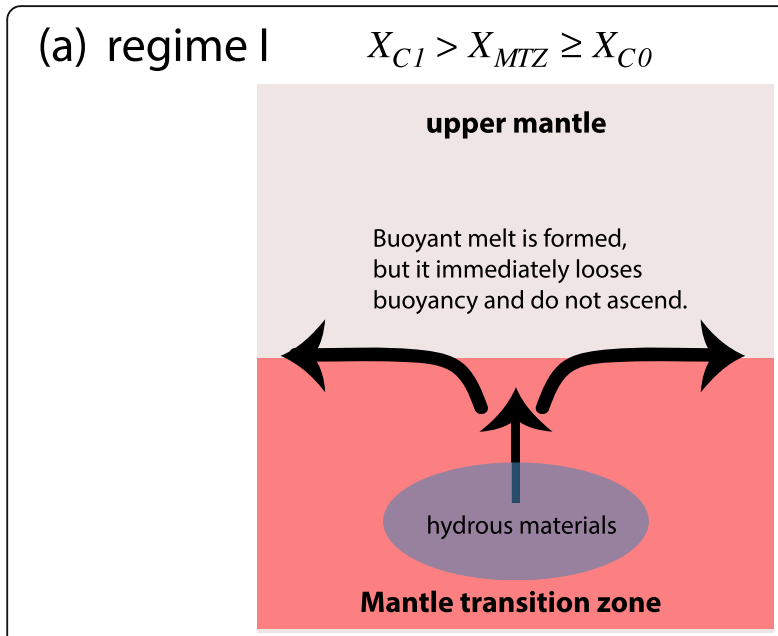

(b) regime II $\quad X_{C 2}>X_{M T Z} \geq X_{C 1}$

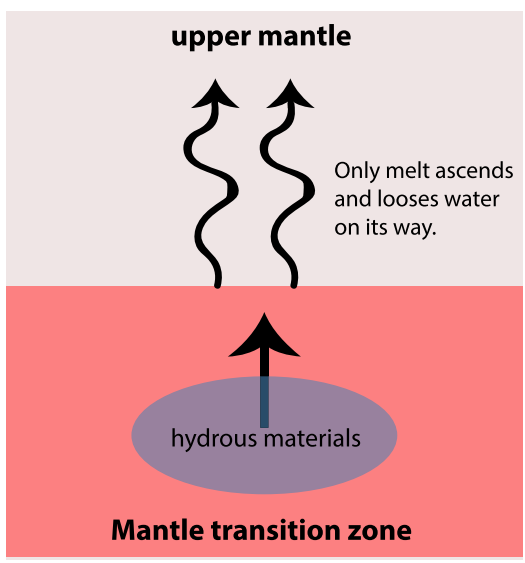

\section{(c) regime III}

$$
X_{M T Z} \geq X_{C 2}
$$

\section{upper mantle}

wet plume

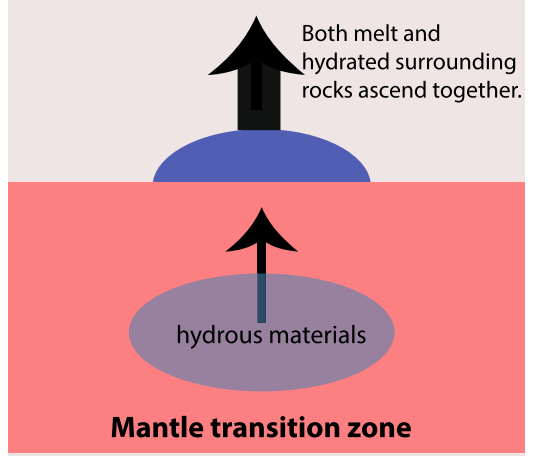

Fig. 11 Cartoons showing how water is transported across the cool regions of $410 \mathrm{~km}\left(S_{C}\right.$ in Fig. 9). In a cool region, when water-rich buoyant materials $\left(X_{M T Z} \geq X_{C O}\right)$ move up to $\sim 410 \mathrm{~km}$, a buoyant melt is formed. a Regime I: If $X_{\text {MTZ }}$ is small $\left(X_{C 1}>X_{\text {MTZ }} \geq X_{C O}\right)$, water in the melt is removed to surrounding minerals immediately and melt does not ascend. $\mathbf{b}$ Regime II: When $X_{M T Z}$ exceeds a critical value $\left(X_{M T Z} \geq X_{C 1}\right)$, melt does not lose its buoyancy immediately. However, if $X_{M T Z}$ is not very high $\left(X_{C 2}>X_{M T Z} \geq X_{C 1}\left(X_{C 1} \sim 0.2 \%, X_{C 2} \sim 1 \%\right)\right)$, then surrounding minerals remain dry and heavy, and only melt ascend (regime II). In this case, ascending melt will lose most water to the surroundings, and not much water is transported to the shallow region. c Regime III: When $X_{\text {MTZ }}$ is high $\left(X_{\text {MTZ }} \geq X_{C 2}(\sim 1 \%)\right)$, then wet melt hydrates surrounding minerals extensively, and melt and minerals together become buoyant. They ascend together to transport water to the shallow regions. Wet materials migrate up in the MTZ as well, but the velocity of transportation of wet materials is much faster in the upper mantle than in the MTZ due to the difference in solid viscosity between these regions

However, buoyant melt does not always carry water upward efficiently (Fig. 11). When a buoyant melt moves upward in the upper mantle made of relatively dry rocks, some water is removed from the melt to the surrounding rocks. When the initial water content of the MTZ materials $\left(X_{\mathrm{MTZ}}\right)$ is small $\left(X_{C 1}>X_{\mathrm{MTZ}} \geq X_{C 0}\right.$; regime $\left.\mathrm{I}\right)$, then melt fraction is small and migrating melt will lose its water immediately and the melt becomes denser and does not migrate up. However, when the water content of the MTZ is higher, then the melt fraction is higher $\left(X_{\mathrm{MTZ}} \geq X_{C 1}\right)$ and the hydrous melt above the $410 \mathrm{~km}$ will keep its buoyancy and migrates up to transport water to the shallower regions. However, when the initial water content $\left(X_{\mathrm{MTZ}}\right)$ is less than a critical value $X_{C 2}$ $\left(X_{C 2}>X_{\mathrm{MTZ}} \geq X_{C 1}\right.$; regime $\left.\mathrm{II}\right)$, surrounding minerals are not much hydrated and remain dense (because they are cool) and stay in their original location and only melt migrates upward. In this case, the melt will eventually lose its water during ascent, and not much water is transported to the shallow mantle. When the initial water content $\left(X_{\mathrm{MTZ}}\right)$ is larger $\left(X_{\mathrm{MTZ}} \geq X_{\mathrm{C} 2}\right.$; regime III), then a larger amount of hydrous melt will be formed and therefore hydration of surrounding materials is extensive and the whole materials (hydrous melt + hydrated minerals) become buoyant to form a hydrous plume. Using the lever rule (mass balance), melt and solid density and water partitioning considerations, we estimate $X_{C 1} \approx 0.2 \mathrm{wt} \%$ and $X_{C 2} \approx 1$ wt $\%$ for the temperature difference of $300{ }^{\circ} \mathrm{C}$ (Supplementary Material).

The critical water content is proportional to the temperature difference. If the temperature is too low, then the critical water content will be too large and wet plume will not be formed. However, cold regions (e.g., regions with stagnant slabs) will be warmed up with time, and at a certain point temperature becomes warm enough (but still colder than most regions) to produce wet plumes. 
In short, when materials with water content exceeding the threshold water content $\left(X_{C 2}\right)$ are transported to the shallower regions, all materials will ascend. The flux of water transported by this process is given by $S_{C} \cdot X_{\mathrm{MTZ}}$. $U_{\text {plume }} \cdot \rho\left(S_{C}\right.$ : cool area where this mechanism operates (area where $X_{\mathrm{MTZ}} \geq X_{C 2}$ ), $U_{\text {plume }}$ : the upwelling velocity of a plume, $\rho$ : the density of upwelling materials). Since the upwelling velocity of a plume depends on the buoyancy, $U_{\text {plume }}=U_{\text {plume }}^{0} \frac{X_{\mathrm{MTZ}}-X_{\mathrm{C} 2}}{\left\langle X_{\mathrm{MTZ}}-X_{\mathrm{C} 2}\right\rangle}\left(\left\langle X_{\mathrm{MTZ}}-X_{C 2}\right\rangle \approx 0.015 \%\right.$ (Supplementary Material): the mean value of $X_{\mathrm{MTZ}}-$ $X_{C 2}, \quad U_{\text {plume }}^{0} \approx 1 \mathrm{~m} /$ year (Yuen and Peltier 1980). Note that this is the ascending velocity of a plume in the upper mantle. Hydrous materials are buoyant in the deeper mantle and they will also ascend (except near subduction zones), but the velocity of ascent is much slower because of the higher viscosity in the deeper mantle.

Motivated by the recent rapid sea-level drop (Fig. 6) associated with the old age of subducting slabs (Müller et al. 2016), we assume initial excess regassing (addition of excess water to the MTZ by subduction of old deeply hydrated plates) during a time span of $\tau_{1}(=100 \mathrm{Myr})$ (Fig. 12). During this process, the ocean mass decreases. Excess water transported to the deep mantle promotes melting in the shallow lower mantle producing highly hydrous melt. An MRL is formed in the uppermost lower mantle (LVL-750). When plate geometry changes due to the supercontinental cycle (e.g., LithgowBertelloni and Richards 1998), the water-rich materials formed in the subduction zone (LVL-750) will be located away from the subduction zone. Because these waterrich materials are less dense than the surrounding materials, they will move upward to join the MTZ. A region of hydrous materials (low seismic velocity) will be formed in the MTZ. When these materials move up into cold regions just above $410 \mathrm{~km}$ boundary, then hydrous melt is formed that promotes a wet plume to enhance degassing from the MTZ. The transition time from the excess regassing to excess degassing $\left(\tau_{2}\right)$ is determined by the time scale of a change in plate geometry associated with supercontinental cycle and is on the order of 100-200 Myrs (Lithgow-Bertelloni and Richards 1998). In our approach, we assume plausible $\tau_{1}$ and $\tau_{2}$, and seek how big an area of MTZ-derived volcanism $\left(S_{C}\right)$ would be needed to explain the negative feedback.

Therefore, the evolution of the MTZ water content in response to a regassing pulse can be described as

$$
\begin{aligned}
M_{\mathrm{MTZ}} \frac{d \Delta X_{\mathrm{MTZ}}}{d t}= & \Delta \Gamma_{\mathrm{MTZ}}^{+} \cdot F^{+}(t)-\Delta \Gamma_{\mathrm{MTZ}}^{-} \\
& \cdot F^{-}(t)
\end{aligned}
$$

where $\Delta X_{\mathrm{MTZ}}$ is the change in the MTZ water content caused by an excess regassing, $\Delta \Gamma_{\text {MTZ }}^{+}$is the amplitude of excess regassing (we use a value consistent with the sea level change of $2-3 \mathrm{~m} / \mathrm{Myr}), \Delta \Gamma_{\mathrm{MTZ}}^{-}$is the amplitude of excess degassing that is proportional to $S_{C} \cdot\left(X_{\mathrm{MTZ}}-\right.$ $X_{C 2}$ ), and $F^{+}(t), F^{-}(t)$ are the functions of time that include $\tau_{1}$ and $\tau_{2}$ respectively (for details, see Supplementary Material). Because the excess degassing rate is proportional to $\left(X_{\mathrm{MTZ}}-X_{C 2}\right)$, this effect provides a negative feedback and stabilizes the transition zone water content.

We show the results of calculated $X_{\mathrm{MTZ}}(t)$ during and after the regassing pulse for various values of $S_{C}$ and $\tau_{2}$ (Fig. 13). Using an approximate mass balance relationship (Eq. 3), we calculate the sea-level history from

$$
\frac{\Delta z}{\bar{z}}=-\frac{M_{M T Z}}{W_{\text {ocean }}} \cdot \Delta X_{M T Z}
$$

where $\Delta z$ is the sea-level change, $\bar{z}$ is average ocean depth, and $W_{\text {ocean }}$ is the ocean mass.

Note that a relatively large change in the sea-level correlates with a small change in $X_{\mathrm{MTZ}}$, illustrating the buffering function of the MTZ for the ocean mass. It is seen that, with $S_{C} \geq 10^{10} \mathrm{~m}^{2}$, this model explains the rapid degassing following a rapid regassing. This $S_{C}$ is a substantially smaller area compared to the area of mid-ocean ridge volcanism $\left(7 \times 10^{12} \mathrm{~m}^{2}\right)$. The main reason for the efficient degassing by this mechanism is that both the ascent velocity of water-rich materials $\left(U_{\text {plume }}\right)$ and the water content of upwelling materials $\left(X_{\mathrm{MTZ}}\right)$ are much larger than the same properties associated with the midocean ridge volcanism.

\section{Discussion}

6.1 Evidence of partial melting above and below the MTZ Seismic evidence for the LVL-410 is widespread from ScS reverberations (Revenaugh and Sipkin 1994), receiver functions (Tauzin et al. 2010; Vinnik and Farra 2007), and body-wave triplications (Song et al. 2004), consistent with this expectation. Wei and Shearer 2017 found evidence of LVL-410 over $33-50 \%$ of the Pacific Ocean region with reflected $S$ waves. Higher-frequency Ps receiver functions show evidence for LVZ-410 associated with localized MTZ upwelling near the Japan slab (Liu et al. 2016) and surrounding the European Alps (Liu et al. 2018).

Evidence for LVL-750 is more sporadic. LVL-750 is observed in regions near subduction zones and other known zones of down-welling (Liu et al. 2016, 2018; Schmandt et al. 2014). Seismological observations on the LVL-750 may also help distinguish whether melt is lighter or heavier than the surroundings. If the melt produced within LVL-750 is heavier than the surrounding rock, then melt will drain downward and therefore melt 
(a)

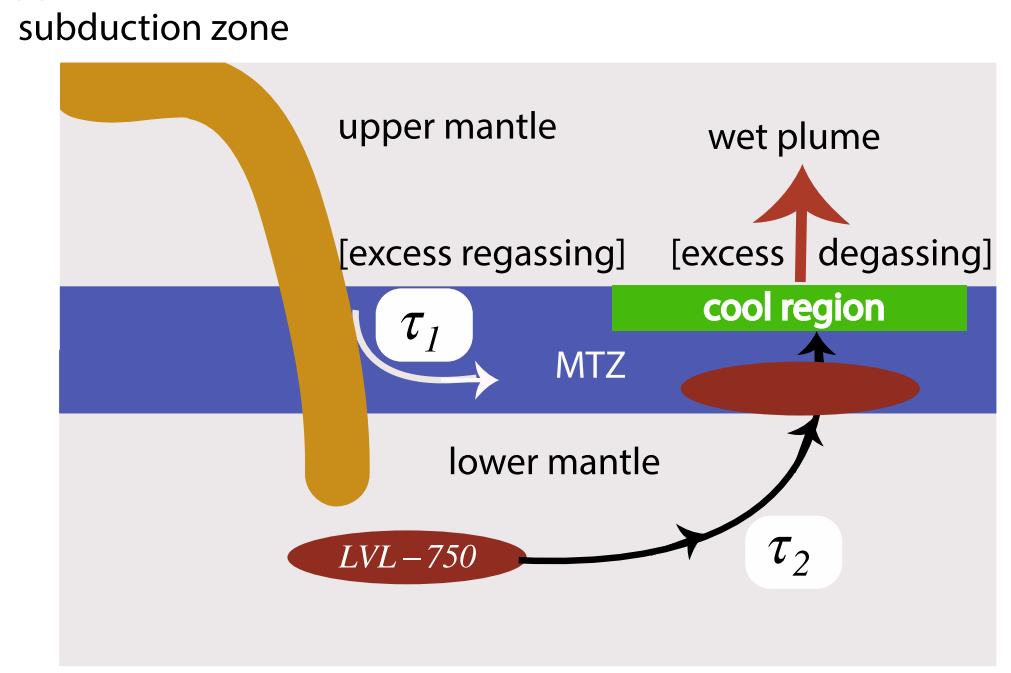

(b)

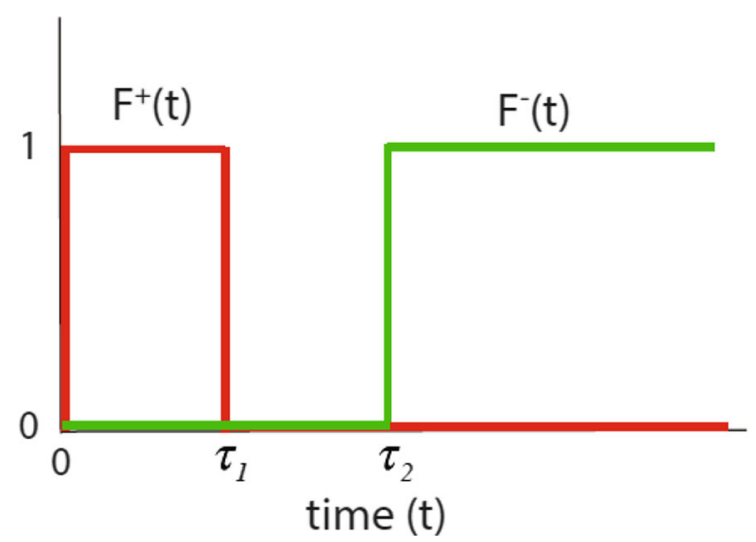

Fig. 12 Model of global water circulation involving deep mantle melting. a A schematic diagram of water circulation. Excess regassing occurs associated with cold subduction ( $\tau_{1}$ : duration of excess regassing). This produces partial melting in the lower mantle (LVL-750). Due to the change in plate boundary geometry (associated with supercontinent cycle (Lithgow-Bertelloni and Richards 1998), the hydrated and buoyant materials will be transported to the MTZ, and when these materials reach to $\sim 410 \mathrm{~km}$, excess degassing starts (after $\tau_{2}$ since the beginning of the excess regassing (this is controlled largely by the time scale of change in plate boundary geometry)). $\mathbf{b}$ Definition of two functions: $\Gamma^{+}(t)$ a function characterizing excess regassing pulse $^{-}(t)$ a function characterizing excess degassing

content near $750 \mathrm{~km}$ will be controlled by the melt production rate. The melt production rate is not well known at this depth, but since melt is produced by water, the melt production rate is on the order of the rate of transportation of water. Given a typical water content in the MTZ of $\sim 0.1 \mathrm{wt} \%$, then the estimated melt fraction near $750 \mathrm{~km}$ for the heavy melt will be $0.5 \%$ (assuming water content in the melt is $20 \%$ ). With the dihedral angle of $30^{\circ}$, this would result in $\sim 1 \%$ velocity reduction (we used the results by Takei 2002 to calculate the velocity reduction). In contrast, for a buoyant melt, melt will be accumulated with a characteristic thickness determined by the solid viscosity and the velocity of the background flow (Fig. 3). The peak melt content is on the order of $5-10 \%$ according to a model by Karato et al. (2006), and therefore we assume a velocity-depth profile shown in Fig. 14a. The results from a model of $\sim 50 \mathrm{~km}$-thick MRL are consistent with the seismological observations of Schmandt et al. (2014), who mapped estimated Vs anomalies ranging from 1.25 to $-2.6 \%$ beneath the central USA. Liu et al. (2016, 2018) imaged smaller Ps converted waves from interfaces below the $660 \mathrm{~km}$ discontinuity with smaller amplitudes, corresponding to $-1.5 \% \mathrm{Vs}$ anomalies beneath the Japan slab and $-0.5-1.5 \%$ Vs anomalies beneath the European Alps. We used models inspired by these parameters to compute synthetic receiver-function responses (Fig. 14b).

In this calculation, we also considered a model by Gréaux et al. (2019) who suggested that the LVL-750 is 

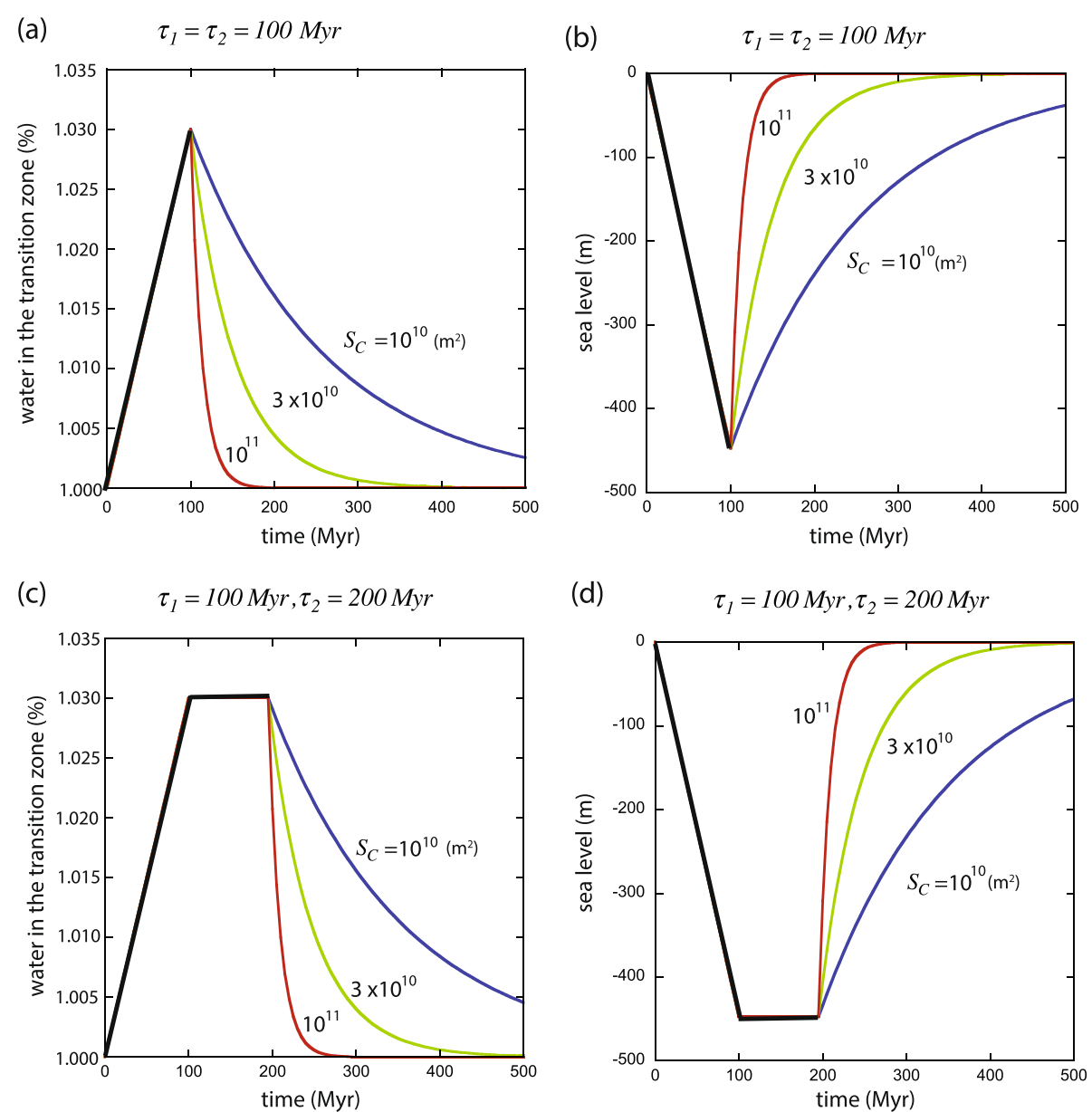

Fig. 13 Results of model calculations on ocean mass history. Regassing parameters (rate of regassing and duration of regassing pulse $\left.\left(\tau_{1}\right)\right)$ are chosen to reproduce the inferred rapid sea-level drop (2-3 m/Myrs (in the last $\sim 100$ Myrs); Fig. 6). Degassing parameters include the area of cool regions with excess degassing $\left(S_{C}\right)$ and the delay time $\left(\tau_{2}\right)$ for degassing since the beginning of excess regassing (and the plume upwelling velocity $\left(\sim 1 \mathrm{~m} /\right.$ year)). a History of the water content in the MTZ $\left(\tau_{1}=\tau_{2}=100 \mathrm{Myrs}\right)$. b Sea-level change corresponding to the model shown in (a) using a relation $\Delta z \approx-\bar{z} \frac{M_{M T} \Delta X_{M I Z}}{W_{\text {OCan }}}\left(\Delta z\right.$ : sea-level change, $\bar{z}$ : average depth of the oceans $(=3730 \mathrm{~m}), M_{M T z}$ : mass of the MTZ $\left(=4 \times 10^{23} \mathrm{~kg}\right)$ ), $\Delta X_{\text {MTZ: }}$ change in the water content of the MTZ; $W_{\text {ocean: }}$ mass of oceans $\left(=1.4 \times 10^{21} \mathrm{~kg}\right)$ ). b Same as $(\mathbf{a})$ except that $\tau_{1}=100 \mathrm{Myrs}$, and $\tau_{2}=200$ Myrs. c Same as (b) except that $\tau_{1}=100$ Myrs, and $\tau_{2}=200$ Myrs. Observed sea-level changes (Fig. 7) can be explained with $S_{C}=(3-10) \times 10^{10}\left(\mathrm{~m}^{2}\right)$ (i.e., a region with $200-350 \mathrm{~km}$ diameter)

caused by a layer of paleo-oceanic crust. This model predicts velocity discontinuity in both top and bottom of the LVL and a double peak in receiver function will result as shown in Fig. 14 (for technical details, see Supplementary Material). This is not consistent with the observations. Therefore, we conclude that seismic observations support a buoyant melt model but not a model invoking the presence of chemically distinct materials such as subducted oceanic crust.

\subsection{Evidence of wet plumes}

We note that a plume produced in the regime III $\left(X_{\mathrm{MTZ}} \geq\right.$ $X_{C 2}$ ) will be geophysically visible, but migrating melt in the regime II $\left(X_{C 2} \geq X_{\mathrm{MTZ}} \geq X_{C 1}\right)$ without substantial hydration of minerals will be hard to detect geophysically. There is evidence from seismic tomography (Tao et al. 2018; Zhang et al. 2018; Zhao and Ohtani 2009) and magnetotelluric ( $\mathrm{Li}$ et al. 2020) studies for plumes originated from the MTZ. Those might correspond to plumes formed under the condition of $X_{\mathrm{MTZ}} \geq X_{\mathrm{C} 2}$. We also note that geophysical anomalies in the Appalachian (Evans et al. 2019) might represent evidence for a wet plume associated with the breakup of the Pangea. In addition to geophysical observations, geochemical observations suggest the important contributions of MTZ materials to the composition of some volcanic rocks (e.g., Bonatti 1990; Kuritani et al. 2013; Li et al. 2020; Metrich et al. 2014; Nichols et al. 2002; Sobolev et al. 2019). 


\section{(a) \\ Model AK135 \\ Model Perturbations}

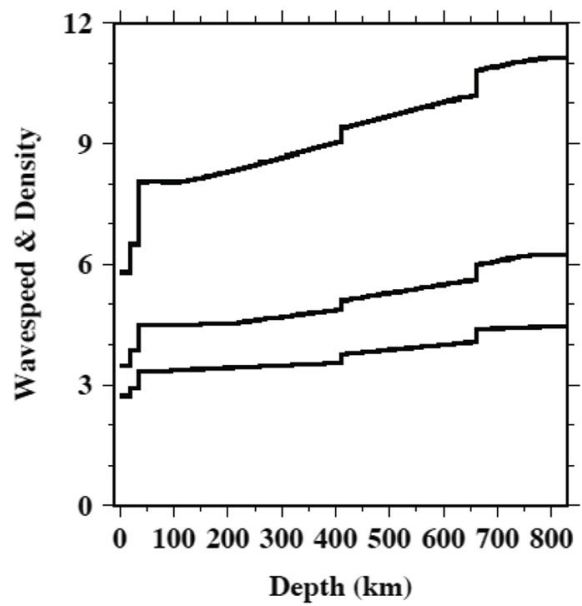

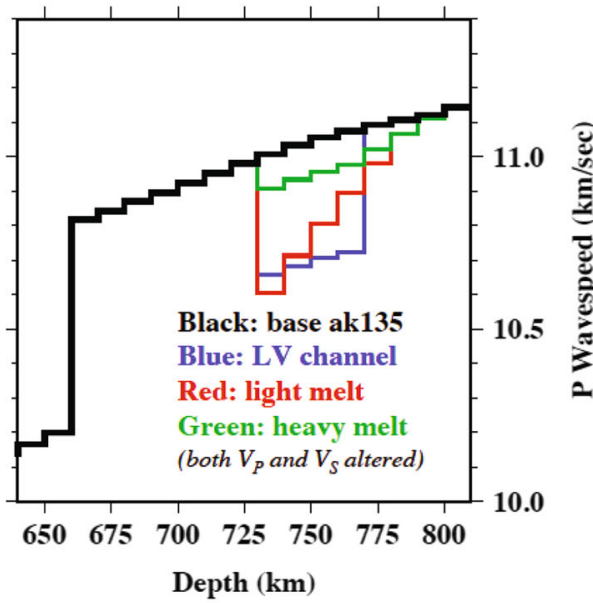

$\mathrm{f}_{\mathrm{c}}=0.5 \mathrm{~Hz}$

$\mathrm{f}_{\mathrm{c}}=\mathbf{1 . 0 \mathrm { Hz }}$

Depth $(\mathbf{k m})$

(b)

$\mathrm{f}_{\mathrm{c}}=\mathbf{2 . 0 \mathrm { Hz }}$
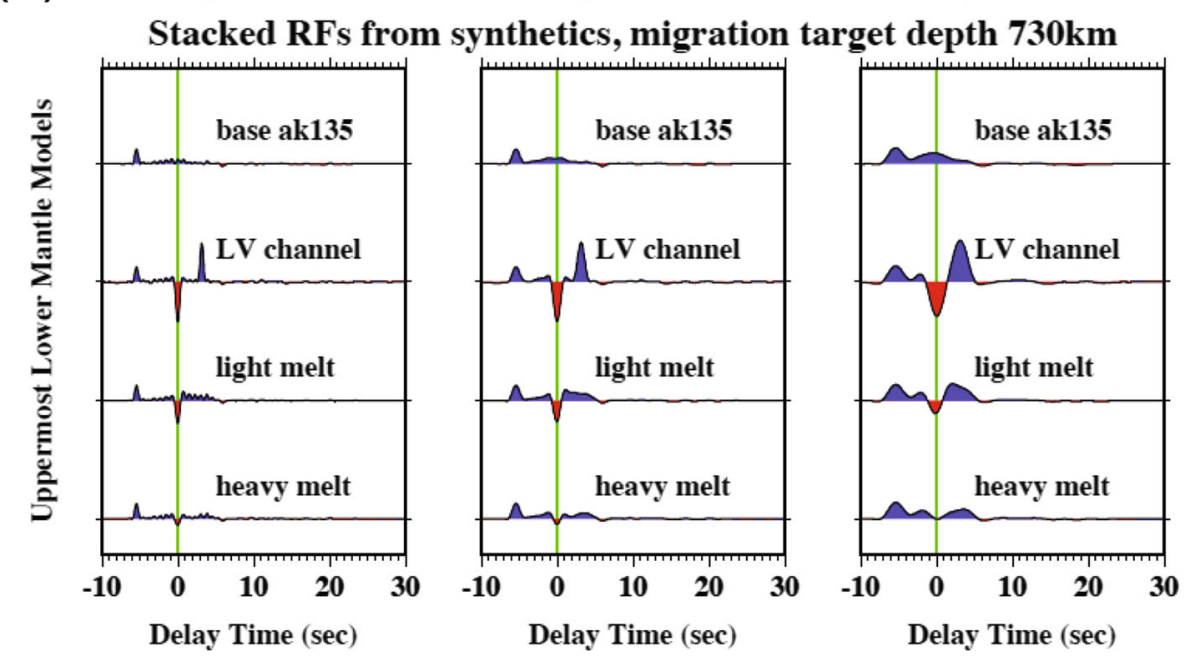

Fig. 14 Results of forward modeling of receiver functions for various models of LVL-750. a The velocity-depth relationship for various models of a LVL at $\sim 750 \mathrm{~km}$. b Corresponding receiver function. Three models are considered: (1) A low velocity channel cause by the presence of chemically distinct materials such as subducted oceanic crust (e.g., (Gréaux et al. 2019)). (2) A case for a heavy melt. In a region of down-welling background flow (i.e., subduction zones), heavy melt will drain down and there is no melt accumulation. Consequently, velocity is only slightly lower than the background velocity. (3) A case for a light melt. Light melt will be accumulated in s region of down-welling background flow (i.e., subduction zones) and a melt-rich layer will be formed resulting in a substantial velocity reduction near the top of the melt-rich layer

\subsection{Water content of the mantle transition zone}

In our model, the water content in the MTZ is buffered by the melting relationship: water re-distribution by melting and resultant melt-solid separation. In the simplest version of our model, water of the MTZ is transported to the shallow upper mantle by buoyant plumes (regime III), and this critical water content is $X_{C 2} \approx 1 \%$. This percentage agrees reasonably well with the water content of the MTZ in the east Asia (Karato 2011; Suetsugu et al. 2006). Our model also suggests that degassing from the MTZ can occur at lower water content, or in an earlier stage of
MTZ degassing, for $X_{\mathrm{MTZ}} \geq X_{C 1} \approx 0.2 \%$. Therefore, the model presented here would apply for heterogeneous MTZ water content ranging from 0.1 to $1.0 \%$, consistent with some geophysical estimates (Karato 2011; Li et al. 2013; Suetsugu et al. 2006; Wang et al. 2019a).

\subsection{Comparison to other models}

Previous studies on the evolution of the ocean mass may be classified into two categories: (i) studies of the longterm evolution of ocean mass on 0.5-4.0 Ga time scales (e.g., Crowley et al. 2011; Franck and Bounama 2001; 
Korenaga 2011; McGovern and Schubert 1989; Nakagawa et al. 2018; Nakagawa et al. 2015; Rüpke et al. 2006)), and (ii) studies on 10-100 Ma time scales, with the focus on explaining the observed sea level change in the Phanerozoic (e.g., Gurnis 1993; Karlsen et al. 2019).

Most studies did not consider the role of the MTZ and therefore their models do not explain a high water content with the MTZ. An exception is Nakagawa et al. (2015) where the role of the MTZ was included through the transport of water-rich paleo-oceanic crust into the MTZ. Nakagawa's model can explain the high water content of the MTZ, but the results depend strongly on the assumed water content of the oceanic crust and the efficiency of transport of crustal materials to the MTZ. The way in which subducted oceanic crust may be mixed into the MTZ is poorly understood and highly controversial (e.g., Gaherty and Hager 1994; Karato 1997; van Keken et al. 1996). At this stage, the Nakagawa model does not explain the cycling of deep-mantle water that likely regulates the ocean mass.

In some studies of long-term ocean evolution, feedbacks through water-sensitive rheology are considered (e.g., Crowley et al. 2011; McGovern and Schubert 1989; Schaefer and Sasselov 2015). However, the way in which water-sensitive rheology should be included in such an approach is not clear. First, although water sensitivity of rheological properties is relatively well known for uppermantle minerals such as olivine (e.g., Karato and Jung 2003; Mei and Kohlstedt 2000a, 2000b), water sensitivity of rheological properties within the lower mantle minerals is unconstrained by experiment. Water may have negligible effects on rheological properties of the lower mantle mineral ( $\mathrm{Mg}, \mathrm{Fe}) \mathrm{O}$ (Otsuka and Karato 2015). Second, if the plastic flow occurs via diffusion creep (e.g., Karato et al. 1995), then water would increase the viscosity through enhanced grain-growth kinetics, and in such a case, the water effect is to make materials stronger. Third, following the concept that water may affect the thickness of plate through the influence of water on dehydration depth, Korenaga (2011) proposed a model where high water content makes global water cycling slower, an idea that is opposite to a conventional idea proposed by Crowley et al. (2011) and McGovern and Schubert (1989). However, the validity of Korenaga's model can be questioned because the extent to which the strength of the lithosphere controls the overall convection rate is unclear, and also it is not clear if the strength of the lithosphere is controlled mostly by its thickness. Importance of dynamic weakening in friction to control the strength of the lithosphere was proposed by Karato and Barbot (2018).

Perhaps more important is the role of deep mantle melting that could buffer the water content. If we consider degassing only by mid-ocean ridge volcanism, plus a small addition from hotspot volcanism, the water effect is very slow-acting. The whole ocean mass can be created in $\sim 10$ Gyrs. In contrast, regassing via MTZrelated melting starts with "wetter" MTZ rock and concentrates its water in Earth's handful of "wet" plumes. "Wet" plumes would be more efficient because of the much higher water content in these magmas and the higher velocity of transport.

In the studies on the ocean mass evolution for several $100 \mathrm{~s}$ Myr time-scale, the key issue is the interpretation of the sea-level fluctuation (e.g., Gurnis 1993; Karlsen et al. 2019 ). The sea-level record for the Phanerozoic Eon shows medium-term fluctuation with a time scale of $\sim 100$ Myrs (Fig. 6). Previous studies tried to explain the fluctuation by invoking a direct link between surface plate motion and the sea-level change, considering only shallow mantle processes. The main motivation for such models is the similarity between the sea-level record and the inferred history of plate motions in this period. For example, during the last $\sim 400$ Myrs, the supercontinent Pangea was formed at $\sim 300 \mathrm{Ma}$ and started to break up at $\sim 170$ Ma (e.g., Condie 1998 ). During this interval, the motion of plates changed dramatically including the location of subduction zones and ridges as well as the average plate velocity (Lithgow-Bertelloni and Richards 1998; Müller et al. 2016). Although the details of plate motion history are controversial (see also Korenaga 2007; Korenaga et al. 2017; Torsvik and Cocks 2019), it is clear that when a supercontinent exists, the mean plate size is large and hence the age of subducting plate is old, leading to high regassing rate. In contrast, when a supercontinent is broken into small pieces, the mean age of subducting plates is young and regassing rate is less. Also the young mean age will make sea-level higher. Consequently, such a model explains some of the observed sea-level history.

One obvious limitation of these models is that because they do not consider deep mantle processes, they cannot explain the high water content of the MTZ. Another limitation is that because these models accept enhanced regassing but their model of corresponding enhanced degassing in only modest, ocean mass should have been declining through the geological history. The amount of sea-level drop during the enhanced regassing is 100-300 m. Supercontinents have cycled a few times in Earth's history (Condie 1998; Nance and Murphy 2013), and consequently, the net drop of sea-level would be more than several $100 \mathrm{~m}$ implying that a large areas of continents should have been flooded in the Precambrian time. This is not observed in the sea-level record (e.g., Eriksson 1999; Wise 1972, 1974).

We should note that there is a possible way to test our model through the study of processes of supercontinent breakup. During the assembly of a supercontinent, the 
subduction of old plates will be vigorous. Some plate would form stagnant slabs in the MTZ, as seismology images now in Eastern Asia. The stagnant slabs will form cold MTZ below the supercontinent. According to our model, these regions are prone to produce wet plumes. Wet plumes will weaken the lithosphere and hence help breakup of the supercontinent. There are some reports suggesting a link between plumes and supercontinents (e.g., El Dien et al. 2019; Le Pichon et al. 2019; for the link between volcanism and continental rifting, see also Sengör and Burke 1978). As some of these papers suggest, plumes linked to supercontinent breakup might originate in the lower mantle. However, because deep-mantle plumes must traverse the MTZ, the entrainment and/or melting of hydrated portions of the MTZ may control how water-rich materials are transported to the surface.

Price et al. (2019) developed a three-dimensional model of water transport in the mantle where the influence of deep mantle melting is included. However, in their model, melt is assumed to be lighter than the coexisting rocks in all situations, and rises to the nearsurface region. This assumption would prevent the MTZ from retaining water and is not consistent with the experimental observations on the melt density (Jing and Karato 2012; Sakamaki 2017; Sanloup et al. 2013).

Yang and Faccenda (2020) presented a model to explain the intra-plate volcanism originating from the MTZ such as the Changbaishan volcano in the NorthEast China. They assume the formation of highly hydrous and buoyant melt similar to our model, but they did not discuss the implications of this type of volcanism to the global water circulation and the stability of the ocean mass. Also, some key essence such as the water transport rate is not discussed by Yang and Faccenda (2020).

\subsection{Remaining issues}

In our model presented here, the emphasis is to evaluate the role of deep mantle melting in a semi-quantitative fashion to see if deep-mantle melting can buffer the MTZ water content and consequently the ocean mass. In doing so, we left a few key issues unexplored:

\subsubsection{The efficiency of degassing (water transport from solid Earth to oceans)}

Degassing processes to add water to the oceans are given by the product of the flux of water in the materials transported to the near surface times efficiency of degassing. At mid-ocean ridges, basaltic magmas are transported to the ocean bottom, and upon cooling some water is added to the oceans. But some water in basalts remains in basalts (as water trapped in intrusive rocks).
In most models, this efficiency is assumed to be a constant on the order of $50 \%$ (e.g., Rüpke et al. 2006).

In a new type of degassing proposed here, water-rich materials are transported to near-surface regions in the continental regions. It is not clear how water transported to near surface regions in the continents adds water to oceans. Those volcanoes add water and other volatiles to the atmosphere and to the surface rocks. Water in the atmosphere will be added to oceans eventually through ocean-atmosphere mass exchange. Similarly, water in surface rocks will eventually be added as sediments and this will in turn enhance degassing by the arc magmatism in subduction zones. Also, it is possible that some of these volcanisms are related to continental rifting (e.g., Sengör and Burke 1978). If rifting develops enough, then new oceans will be formed and water will be added directly. In such a case, we expect high degassing rate from these volcanoes and ocean ridges in the incipient stage of supercontinent breakup.

Water-rich plumes may not be limited to continental regions. If old plates subduct in oceanic regions, and cool the transition zone, then wet plumes could also be formed in the oceanic environment. All of these details need to be investigated.

\subsubsection{The role of plate motion history}

In the current version of our model, the role of plate motion history is included only implicitly. Namely, when we introduce excess regassing followed by excess degassing caused by deep mantle melting, we assumed the time function characterizing excess regassing and degassing $\Gamma^{+,-}(t)$ where plate history is included. It is important to investigate the nature of these functions by incorporating the realistic plate motion history.

In the same token, we did not consider the role of change in the average age of oceanic plates that may modify the sea level. If the variation in the mean age of oceans is as large as suggested by Müller et al. (2016), this effect needs to be included in analyzing the sea-level history to understand the evolution of the ocean mass. For example, Karlsen et al. (2019) tried to explain the sea-level history of the last $\sim 210$ Myrs based on the plate motion history by Müller et al. (2016). Consequently, the sea-level high at $\sim 100 \mathrm{Ma}$ is explained by the change in the mean age of oceanic plates rather than enhanced degassing by Karlsen et al. (2019).

\subsubsection{Characterization of wet plumes from the MTZ}

A key concept proposed in this paper is efficient water transport from the MTZ to the surface in the cooler regions of the MTZ via wet plumes. As reviewed before, a number of geophysical observations suggest the presence of presumably wet plumes from the MTZ particularly in the East Asia. The present model predicts that such 
volcanism was likely more extensive just before and after the breakup of a super continent $(\sim 170 \mathrm{Ma}$ in case of Pangea). More geological, geochemical, and geophysical studies need to be made to characterize the nature of these volcanisms. Geochemical studies will be particularly important to assess the history of these volcanisms.

\subsubsection{Water content in the lower mantle}

Our model suggests that the lower mantle has substantially smaller water content than the MTZ. This notion is not confirmed because there is no constraint on the water content of the lower mantle. One promising way is to extend the study on electrical conductivity. There are two ways in which we should do this. First, geophysical estimates of lower mantle conductivity are still not mature (e.g., Kelbert et al. 2019; Kelbert et al. 2009; Kuvshinov 2012). Second, essentially nothing is known on the influence of water (hydrogen) in electrical conductivity of lower mantle minerals. By analogy of ceramic materials, one expects that hydrogen enhances electrical conductivity of bridgmanite (Navrotsky 1999), but the experimental studies to test this hypothesis have not been made. Although there are some studies on the electrical conductivity in bridgmanite and $(\mathrm{Mg}, \mathrm{Fe}) \mathrm{O}$, the role of water (hydrogen) was not studied in any detail. Given the recent experimental study showing relatively high water solubility in bridgmanite in the shallow lower mantle (Fu et al. 2019), and increased water solubility in $(\mathrm{Mg}, \mathrm{Fe}) \mathrm{O}$ at elevated pressures (Otsuka and Karato 2015), it is urgent to test this hypothesis.

\subsubsection{Influence of water dependent rheology}

In the first study of the ocean mass history, McGovern and Schubert (1989) focused on the influence of water content sensitive rheology on the history of degassing. Similar studies were made by Crowley et al. 2011 and Franck and Bounama (2001) (we note that Rüpke et al. 2006 and van Keken et al. 2011 did not consider the feedback between water-dependent rheology and global water cycling). In our approach, water-dependent rheology does not have a direct feedback to the global water circulation because the water flux is determined largely by the melting relationship. However, rheological properties change the rate of ascent of wet plumes.

\subsubsection{Wetting relation of melts in lower mantle minerals}

There is only one report on the wetting relationship of melt with minerals under the shallow lower mantle conditions (Panero et al. 2015) showing non-wetting behavior (dihedral angle $\sim 30^{\circ}$ ). If melts completely wet grainboundaries in the lower mantle, then seismologically detected low velocity region starting at $\sim 750 \mathrm{~km}$ would mean the depth at which melting starts, but it will not constrain the melt density.

\subsection{Water cycling in the geologic history}

Earth has been cooling and therefore the melting regime has likely evolved with time. When mantle temperature was very high, melts formed above $410 \mathrm{~km}$ would be water-poor and dense. Heavy melts above the $410 \mathrm{~km}$ would linger and eventually return to the MTZ. Consequently, water added to the MTZ remained there, decreasing the ocean mass over time. However, since the regassing rate is also low in a hot young Earth, not much water subducted into the mantle.

As Earth's mantle cooled, melts formed above the MTZ would have more water in general. At this stage, melts formed in cooler regions will have a sufficiently large amount of water to form wet plumes, if the water content of the MTZ materials in these regions exceeds a critical value: now the water valve starts to regulate the water content of the MTZ (and hence the ocean mass). With further cooling in Earth's future, the temperature in the MTZ will eventually become too low to induce partial melting within convecting masses that cross the $410 \mathrm{~km}$ discontinuity. At this point, water-rich materials in the MTZ will be transported out of the MTZ without melting, no heavy melt will return to the MTZ, and mantle water content will lose its peak concentration within the MTZ. Ocean mass would not be regulated and can be predicted to decrease with time due to cold subduction, effecting a large regassing rate without a corresponding large degassing rate.

\section{Summary and perspectives}

We reviewed our current understanding of the global water circulation including water storage capacity of the mantle, water distribution in the mantle, melting relationship in the mantle (particularly across the MTZ), melt density relative to solid density, and geophysical and geochemical observations related to partial melting and the distribution of wet materials. We conclude that there is a peak in water content in the MTZ and there is strong evidence for partial melting both above and below the MTZ. Sea-level history during the Phanerozoic period (to $\sim 540 \mathrm{Ma}$ ) is also reviewed that shows large fluctuation on 10-100 Ma time scales but a nearly constant long-term average. Causes for sea-level variation are reviewed including tectonic origin and the changes in the ocean mass.

Focusing on partial melting and melt transport around the MTZ, we present a conceptual model that explains two important geological/geophysical inferences in a unified fashion: the high water content of the MTZ and the long-term stability of the sea-level despite the shortterm large variations. However, the details of the model remain uncertain. One major limitation is that it is a one-dimensional model where the influence of horizontal mass transport is only roughly included. Extending 
this model to three-dimensions including a realistic history of plate boundary geometry (history of mantle convection) would be important.

An important conclusion from this model is that, in addition to well-known melting at mid-ocean ridges, deep mantle melting likely influences the global water circulation substantially. So far, much of the focus in the study of global water circulation has been on the volcanism associated with the MORB. But the MORB is essentially dry $(\sim 0.1 \mathrm{wt} \%$ water $)$ and its contribution to the ocean mass budget is not so large. In contrast, deep melts are water-rich $(\sim 5-10 \mathrm{wt} \%$ water $)$ and hence could make an important contribution to the global water circulation. Evidence for transition zoneoriginated melt is identified by geochemical studies (Kuritani et al. 2013; Sobolev et al. 2019). Seismological studies also show low-velocity regions across the MTZ suggesting partial melting in these regions (Tao et al. 2018; Zhang et al. 2018; Zhao and Ohtani 2009). Also, a study on electrical conductivity suggests upwelling of water-rich materials from the MTZ (e.g., Li et al. 2020). However, details of how water transported by wet plumes is added to the oceans are not well known. Some of the wet materials might accumulate below the continents (Griffin et al. 2013), although some water in these regions will eventually be transported to the surface by shallow volcanism. Further studies on these volcanisms will be warranted to better understand the global water circulation and why Earth is a habitable planet.

From the planetary science perspectives, in order for the proposed water valve to operate in a planet, there must be a transition zone in the mantle. Consequently, the size of a planet should be substantially larger than Mars ( 0.1 of Earth mass), a planet whose transition zone is located at the bottom of its silicate mantle (e.g., Spohn et al. 1998). But the planetary mass should be smaller than $~ 10$ Earth mass; otherwise, it will be a gaseous planet (e.g., Hayashi et al. 1985; Rogers et al. 2011). In addition, plate tectonics must operate to maintain extensive material circulation including the oceans and planetary interiors. For plate tectonics to occur on a terrestrial planet, the lithosphere must be relatively weak (e.g., Bercovici 2003; Karato 2014b; Karato and Barbot 2018). The surface temperature is presumably the most important parameter to determine the strength of the lithosphere (e.g., Foley et al. 2012; Karato and Barbot 2018): surface temperature must be low enough to allow brittle fracture with unstable fault motion (Karato and Barbot 2018). This critical temperature is $\sim 700 \mathrm{~K}$. In summary, the habitability conditions where the ocean mass remains nearly constant for billions of years are the modest mass of a terrestrial planet $(\sim 0.2 \times$ to $\sim 10 \times$ of Earth mass) in addition to the appropriate distance from the star. Long-term presence of oceans under these conditions is secured partly through the deep mantle melting that regulates the water content of the mantle and the ocean mass.

\section{Supplementary information}

Supplementary information accompanies this paper at https://doi.org/10. 1186/s40645-020-00379-3.

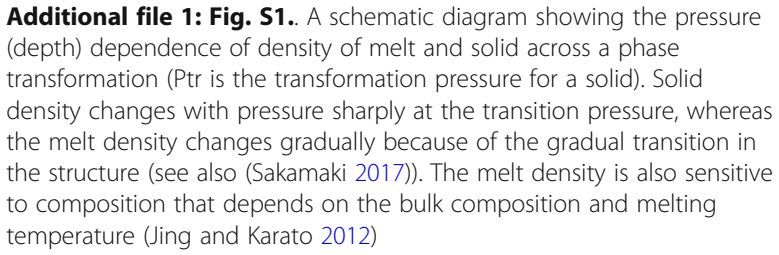

Additional file 1: Fig. S1. A schematic diagram showing the pressure (depth) dependence of density of melt and solid across a phase transformation (Ptr is the transformation pressure for a solid). Solid density changes with pressure sharply at the transition pressure, whereas the melt density changes gradually because of the gradual transition in the structure (see also (Sakamaki 2017)). The melt density is also sensitive to composition that depends on the bulk composition and melting temperature (Jing and Karato 2012)

\section{Abbreviations}

MTZ: Mantle transition zone; MORB: Mid-ocean ridge basalt; OIB: Oceanisland basalt; MRL: Melt-rich layer; LVL: Low velocity layer; LVL-410: Lowvelocity layer above $410 \mathrm{~km}$ depth; LVL-750: Low-velocity layer at around 750 km depth; UM: Upper mantle; LM: Lower mantle

\section{Acknowledgements}

We received constructive criticisms, from reviewers Jiangfeng Yang and an anonymous reviewer that improved the manuscript. A meticulous work by Craig Bina as an editor is highly appreciated. We thank David Bercovici for a discussion on the melt-rich layer, David Evans for the supercontinent cycles, Jun Korenaga on the interpretation of the sea-level, and Motohiko Murakami on the melt density. Marc Hirschmann, Takashi Nakagawa, Jim Ni, Alexander Sobolev, Dave Stevenson, Doug Wiens, Dave Yuen and Shijie Zhong also provided useful discussions/comments.

\section{Authors' contributions}

SK proposed the topic, conceived and designed the study, and developed the model and calculated the sea-level history. BJ carried out the computational study on melt density and JP conducted receiver function forward modeling and edited the text. BK and JP collaborated with the corresponding author (SK) in the construction of manuscript. The authors read and approved the final manuscript.

\section{Funding}

The present study is supported by a grant from NSF (EAR-1764271 (for SK) and EAR-1764140 (for BK))

\section{Availability of data and materials}

Data sharing not applicable to this article as no datasets were generated or analyzed

during the current study.

\section{Competing interests}

The authors' declared that they have no competing interest. All institutional and national guidelines for the care and use of laboratory animals were followed.

\section{Author details}

${ }^{1}$ Department of Earth and Planetary Sciences, Yale University, New Haven, CT 06520, USA. ${ }^{2}$ School of Electrical Engineering and Computer Science, Department of Geology and Geophysics, Center for Computation and Technology, Louisiana State University, Baton Rouge, LA 70803, USA.

Received: 27 July 2020 Accepted: 8 October 2020

Published online: 10 December 2020

\section{References}

Andrault D, Bolfan-Casanova N, Lo Nigro G, Bouhifd MA, Garbarino G, Mezouar M (2011) Solidus and liquidus profiles of chondritic mantle: Implications for melting of the Earth across its history. Earth Planet Sci Lett 304:251-259 
Bercovici D (2003) The generation of plate tectonics from mantle convection. Earth Planet Sci Lett 205:107-121

Bercovici D, Karato S (2003) Whole mantle convection and transition-zone water filter. Nature 425:39-44

Billen Ml, Gurnis M (2001) A low viscosity wedge in subduction zones. Earth Planet Sci Lett 193:227-236

Bolfan-Casanova N (2005) Water in the Earth's mantle. Mineralogical Magazine 69: 229-257

Bolfan-Casanova N, McCammon CA, Mackwell SJ (2006) Water in transition zone and lower mantle minerals. In: Jacobsen SD, Lee Svd (eds) Earth's Deep Water Cycle, Washington DC, pp 57-68

Bonatti E (1990) Not so hot 'Hotspots' in the oceanic mantle. Science 250:107111

Cai C, Wiens DA, Shen W, Eimer M (2018) Water input into the Mariana subduction zone estimated from ocean-bottom seismic data. Nature 563: 389-392

Condie KC (1998) Episodic continental growth and supercontinents: a mantle avalanche connection? Earth Planet Sci Lett 163:97-108

Cowan NB, Abbot DS (2014) Water cycling between ocean and mantle: superEarths need not be waterworlds. Astrophysical I 27:27

Crowley JW, Gérault M, O'Connell RJ (2011) On the relative role of influence of heat and water transport on planetary dynamics. Earth Planet Sci Lett 310: 380-388

Demouchy S, Bolfan-Casanova N (2016) Distribution and transport of hydrogen in the lithospheric mantle: A review. Lithos 240-243:402-425

Dixon JE, Leist L, Langmuir J, Schiling JG (2002) Recycled dehydrated lithosphere observed in plume-influenced mid-ocean-ridge basalt. Nature 420:385-389

El Dien HG, Doucet LS, Li Z-X (2019) Global geochemical fingerprinting of plume intensity sugegsts coupling with the supercontinent cycle. Nat Commun 10: 5270

Eriksson PG (1999) Sea level changes and the continental freeboard concept: general principles and application to the Precambrian. Precambrian Res 97: 143-154

Evans RL, Benoit MH, Long MD, Elsenbeck J, Ford HA, Zhu J, Garcia X (2019) Thin lithosphere beneath the central Appalachian Mountains: a combined seismic and magnetoterrulic study. Earth Planet Sci Lett 519:308-316

Faccenda M, Gerya TV, Burlini L (2009) Deep slab hydration induced by bendingrelated variations in tectonic pressure. Nat Geosci 2:790-793

Fei H, Yamazaki D, Sakurai M, Miyajima N, Ohfuji H, Katsura T, Yamamoto T (2017) A nearly water-saturated mantle transition zone inferred from mineral viscosity. Sci Adv 3:e1603024

Foley BJ, Bercovici D, Landuyt W (2012) The conditions for plate tectonics on super-Earths: Inference from convection models with damage. Earth Planet Sci Lett 331-332:281-290

Franck S, Bounama C (2001) Global water cycle and Earth's thermal evolution. J Geodyn 32:231-246

Fu S, Yang J, Karato S, Vasiliev A, Presniakov MY, Gavriliuk AG, Ivanova AG, Hauri EH, Okuchi T, Purejav N, Lin J-F, (2019) Water concentration in single-crystal (Al,Fe)-bearing bridgmanite grown from the hydrous melt: implications for partial melting and the water storage capacity in the Earth's lower mantle. Geophys Res Lett 46, 10346-10357.

Fukao Y, Widiyantoro RDS, Obayashi M (2001) Stagnant slabs in the upper and lower mantle transition zone. Rev Geophys 39:291-323

Gaherty JB, Hager BH (1994) Compositional vs. thermal buoyancy and the evolution of subducted lithosphere. Geophys Res Lett 21:141-144

Garth T, Rietbrock A (2014) Order of magnitude increase in subducted $\mathrm{H}_{2} \mathrm{O}$ due to hydrated normal faults within the Wadati-Benioff zone. Geology 42:207210

Gréaux S, Irifune T, Higo Y, Tange Y, Arimoto T, Liu Z, Yamada A (2019) Sound velocity of $\mathrm{CaSiO}_{3}$ perovskite suggests the presence of basaltic crust in the Earth's lower mantle. Nature 565:218-221

Griffin WL, Begg GC, O'Reilly SY (2013) Continental-root control on the genesis of magmatic ore deposits. Nat Geosci 6:905-910

Gurnis M (1993) Phanerozoic marine inundation of continents driven by dynamic topography above subducting slabs. Nature 364:589-593

Hager BH, Clayton RW (1989) Constraints on the structure of mantle convection using seismic observations, flow models and the geoid. In: Peltier WR (ed) Mantle Convection. Gordon and Breach, New York, pp 657-763

Hayashi C, Nakazawa K, Nakagawa Y (1985) Formation of the solar system, in: Black, D.C., Matthews, M.S. (Eds.), Protoplanets and Planets II. University of Arizona Press, Tuscon, AZ, pp. 1100-1153.
Hirschmann MM, Tenner T, Aubaud C, Withers AC (2009) Dehydration melting of nominally anhydrous mantle: the primacy of partitioning. Phys Earth Planet In 176:54-68

Hirth G, Kohlstedt DL (1996) Water in the oceanic upper mantle-implications for rheology, melt extraction and the evolution of the lithosphere. Earth Planet Sci Lett 144:93-108

Holland HD (2003) The geologic history of seawater. In: Turekian KK, Holland HD (eds) Treatise on Geochemistry. Elsevier, Amsterdam, pp 1-46

Houser C (2016) Global seismic data reveal little water in the mantle transition zone. Earth Planet Sci Lett 448:94-101

Inoue T, Kakizawa S, Fujino K, Kuribayashi T, Nagase T, Greaux S, Higo T, Sakamoto N, Yurimoto H, Hattori T, Sano A (2016) Hydrous bridgmanite: Possible water reservoir in the lower mantle. Goldschmidt Conference, Yokohama

Inoue T, Wada T, Sasaki R, Yurimoto H (2010) Water partitioning in the Earth's mantle. Phys Earth Planet In 183:245-251

Ito E, Harris DM, Anderson AT (1983) Alteration of oceanic crust and geologic cycling of chlorine and water. Geochemica Cosmochemica Acta 47:16131624

Jing Z, Karato S (2011) A new approach to the equation of state of silicate melts: An application of the theory of hard sphere mixtures. Geochim Cosmochim Acta 75:6780-6802

Jing Z, Karato S (2012) Effect of $\mathrm{H}_{2} \mathrm{O}$ on the density of silicate melts at high pressures: Static experiments and the application of a modified hard-sphere model of equation of state. Geochim Cosmochim Acta 85:357-372

Karato S (1997) On the separation of crustal component from subducted oceanic lithosphere near the $660 \mathrm{~km}$ discontinuity. Phys Earth Planet In 99:103-111

Karato S (2006) Influence of hydrogen-related defects on the electrical conductivity and plastic deformation of mantle minerals: A critical review. In: Jacobsen SD, van der Lee S (eds) Earth's Deep Water Cycle. American Geophysical Union, Washington DC, pp 113-129

Karato S (2011) Water distribution across the mantle transition zone and its implications for global material circulation. Earth Planet Sci Lett 301:413-423

Karato S (2012) On the origin of the asthenosphere. Earth Planet Sci Lett 321(322):95-103

Karato S (2014a) Does partial melting explain geophysical anomalies? Phys Earth Planet In 228:300-306

Karato S (2014b) Some remarks on the models of plate tectonics on terrestrial planets: From the view-point of mineral physics. Tectonophysics 631:4-13

Karato S (2015) Water in the evolution of the Earth and other terrestrial planets. In: Schubert G (ed) Treatise on Geophysics. Elsevier, Amsterdam, pp 105-144

Karato S, Barbot S (2018) Dynamics of fault motion and the origin of contrasting tectonic style between Earth and Venus. Sci Rep 8:11884

Karato S, Bercovici D, Leahy G, Richard G, Jing Z (2006) Transition zone water filter model for global material circulation: Where do we stand? In: Jacobsen SD, van der Lee S (eds) Earth's Deep Water Cycle. American Geophysical Union, Washington DC, pp 289-313

Karato S, Jung H (2003) Effects of pressure on high-temperature dislocation creep in olivine polycrystals. Philosophical Magazine, A 83:401-414

Karato S, Zhang S, Wenk H-R (1995) Superplasticity in Earth's lower mantle: evidence from seismic anisotropy and rock physics. Science 270:458-461

Karki BB, Ghosh DB, Maharjan C, Karato S, Park J (2018) Density-pressure profiles of Fe-bearing $\mathrm{MgSiO}_{3}$ liquid: Effects of valence and spin states, and implications for the chemical evolution of the lower mantle. Geophys Res Lett 45:3959-3966

Karlsen KS, Conrad CP, Magni V (2019) Deep water cycling and sea level change since the breakup of Pangea. Geochem Geophys Geosyst 20

Kasting JF, Catling D (2003) Evolution of a habitable planet. Ann Rev Astronomy Astrophys 41:429-463

Katsura T, Yoneda A, Yamazaki D, Yoshino T, Ito E (2010) Adiabatic temperature profile in the mantle. Phys Earth Planet In 183:212-218

Kawamoto T (2004) Hydrous phase stability and partial melt chemistry in $\mathrm{H}_{2} \mathrm{O}-$ saturated KLB-1 peridotite up to the uppermost lower mantle conditions. Phys Earth Planet In 143(144):387-395

Kelbert, A., Bedrosian, P. and Murphy, B. (2019) The first 3D conductivity model of the contiguous United States: Reflections on geologic structure and application to induction hazards, Geomagnetically Induced Currents from the Sun to the Power Grid.

Kelbert A, Schultz A, Egbert G (2009) Global electromagnetic induction constraints on transition-zone water content variations. Nature 460:10031006 
Kite ES, Ford EB (2018) Habitability of exoplanet waterworlds. Astrophysical J 864: 75

Kopparapu RK, Ramirez R, Kasting JF, Eymet V, Robinson TD, Mahadevan S, Terrien RC, Domagal-Goldman S, Meadows V, Deshpande R (2013) Habitable zones around main-sequence stars: New estimates. Astrophysical J 765:131

Korenaga J (2007) Eustasy, supercontinental insulation, and the temporal variability of terrestrial heat flux. Earth Planet Sci Lett 257:350-358

Korenaga J (2011) Thermal evolution with a hydrating mantle and the initiation of plate tectonics in the early Earth. J Geophys Res 116. https://doi.org/10. 1029/2011JB008410

Korenaga J (2018) Estimating the formation age distribution of continental crust by unmixing zircon ages. Earth Planet Sci Lett 482:388-395

Korenaga J, Panavsky NJ, Evans DAD (2017) Global water cycle and the coevolution of the Earth's interior and surface environment. Philosophical Transactions A 20150393

Kuritani T, Kimura J-l, Ohtani E, Miyamoto H, Furuyama K (2013) Transition zone origin of potassic basalts from Wudalianchi volcano, northeast China. Lithos 156-159, 1-12.

Kuritani T, Ohtani E, Kimura J-I (2011) Intensive hydration of the mantle transition zone beneath China caused by ancient slab stagnation. Nat Geosci 4:713716

Kuvshinov AV (2012) Deep electromagnetic studies from land, sea, and space: progress status in the past 10 years. Surv Geophys 33:169-209

Langmuir CH, Broecker WS (2012) How to Build a Habitable Planet, 2nd edn. Princeton University Press, Princeton

Le Pichon X, Sengör AMC, Imren C (2019) Pangea and the lower mantle. Tectonics 38:3479-3504

Leahy GM, Bercovici D (2007) On the dynamics of hydrous melt layer above the transition zone. J Geophys Res 112. https://doi.org/10.1029/2006JB004631

Li J, Wang X, Wang X, Yuen DA (2013) P and SH velocity structure in the upper mantle beneath Northeast China: Evidence for a stagnant slab in hydrous mantle transition zone. Earth Planet Sci Lett 367:71-81

Li S, Weng A, Li J, Shan X, Han J, Tang Y, Zhang Y, Wang X (2020) The deep origins of Cenozoic volcanoes in Northeast China revealed by 3-D electrical structure. Sci China Earth Sci 63:1-15

Litasov K, Ohtani E, Langenhorst F, Yurimoto H, Kubo T, Kondo T (2003) Water solubility in Mg-perovskite and water storage capacity in the lower mantle. Earth Planet Sci Lett 211:189-203

Litasov KD, Shatskiy A, Ohtani E (2013) Earth's mantle melting in the presence of C-O-H-bearing fluids. In: Karato S (ed) Physics and Chemistry of the Deep Earth. Wiley-Blackwell, New York, pp 38-65

Lithgow-Bertelloni C, Richards MA (1998) The dynamics of cenozoic and mesozoic plate motions. Rev Geophys 36:27-78

Liu Z, Park J, Karato S (2016) Seismological detection of low velocity anomalies surrounding the mantle transition zone in Japan subduction zone. Geophys Res Lett 43:2480-2487

Liu Z, Park J, Karato S (2018) Seismic evidence for water transport out of the mantle transition zone beneath the European Alps. Earth Planet Sci Lett 482:93-104

McGovern PJ, Schubert G (1989) Thermal evolution of the Earth: effects of volatile exchange between atmosphere and interior. Earth Planet Sci Lett 96:27-37

McKenzie DP (1985) The extraction of magma from the crust and mantle. Earth Planet Sci Lett 74:81-91

Mei S, Kohlstedt DL (2000a) Influence of water on plastic deformation of olivine aggregates, 1. Diffusion creep regime. J Geophys Res 105:21457-21469

Mei S, Kohlstedt DL (2000b) Influence of water on plastic deformation of olivine aggregates, 2. Dislocation creep regime. J Geophys Res 105:21471-21481

Metrich N, Zanon V, Creon L, Hildenbrand A, Moreira M, Marques FO (2014) Is the "Azores Hotspot" a wetsopt? Insight from geochemistry of fluid and melt inc; usions in olivine of Pico basalts. J Petrol 55:377-393

Mibe K, Fujii T, Yasuda A, Ono S (2006) Mg-Fe partitioning between olivine and ultramafic melts at high pressures. Geochim Cosmochim Acta 70:757-766

Mitrovica JX, Mound JE, Pysklywec RN, Milne GA (2000) Sea-level change on a dynamic Earth. In: Boschi E, Ekström G, Morelli A (eds) Problems in Geophysics for the Next Millennium. Editrice Compositori, Roma, pp 499-529

Mizutani H, Kanamori H (1964) Variation in elastic wave velocity and attenuative property near the melting temperature. J Phys Earth 12:43-49

Müller RD, Seton M, Zahirovic S, Williams SE, Matthews KJ, Wright NM, Shephard GE, Maloney KT, Barnett-Moore N, Hosseinpour M, Bower DJ, Cannon J (2016) Ocean basin evolution and global-scale plate reorganization events since Pangea Breakup. Annu Rev Earth Planet Sci 44:107-138
Nakada M, Lambeck K (1987) Glacial rebound and relative sea level variations: a new appraisal. Geophys J Roy Astron Soc 90:171-224

Nakagawa T, Iwamori H, Yanagi R, Nakao A (2018) On the evolution of the water ocean in the plate-mantle system. Prog Earth Planet Sci 5:51

Nakagawa T, Nakakuki T, Iwamori H (2015) Water circulation and global mantle dynamics: Insight from numerical modeling. Geochem Geophys Geosyst 16. https://doi.org/10.1002/2014GC005701

Nance RD, Murphy JB (2013) Origins of the supercontinent cycle. Geosci Frontiers 4:439-448

Navrotsky A (1999) A lesson from ceramics. Science 284:1788-1789

Nestola F, Smyth JR (2016) Diamonds and water in the deep Earth: a new scenario. Int Geology Rev 58:263-276

Nichols ARL, Carroll MR, Hoskuldsson AL (2002) Is the Iceland hot spot also wet? Evidece from the water contents of undegassed submarine and subglacial pillow basalts. Earth Planet Sci Lett 202:77-78

Ohtani E (1987) Ultrahigh-pressure melting of a model chondritic mantle and pyrolite compositions. In: Manghani MH, a. YS (eds) High-Pressure Research in Mineral Physics. Terra Scientific Publishing Company, Tokyo, pp 87-93

Otsuka K, Karato S (2015) The influence of ferric iron and hydrogen on Fe-Mg interdiffusion in ferropericlase in the lower mantle. Phys Chem Minerals 42:261-273

Panero WR, Pigott JS, Reaman DM, Kabbes JE, Liu Z (2015) Dry (Mg,Fe)SiO perovskite in the Earth's lower mantle. J Geophys Res 120:894-908

Parai R, Mukhopadhyay S (2012) How large is the subducted water flux? New constraints on mantle regassing rates. Earth Planet Sci Lett 317/318:396-406

Parsons B (1982) Causes and consequences of the relation between area and age of the ocean floor. J Geophys Res 87:289-302

Parsons B, Sclater JG (1977) An analysis of the variation of ocean floor bathymetry and heat flow with age. J Geophys Res 82:803-827

Pearson DG, Brenker FE, Nestola F, McNeill J, Nasdala L, Hutchison MT, Matveev S, Mather K, Silversmit G, Schmitz S, Vekemans B, Vincze L (2014) Hydrous mantle transition zone indicated by ringwoodite included within diamond. Nature 507:221-224

Peltier WR (1998) Postglacial variation in the level of the sea: implications for climate dynamics and solid-Earth geophysics. Rev Geophys 36:603-689

Peslier AH, Schönbächler M, Busemann H, Karato S (2017) Water in the Earth's interior: Distribution and origin. Space Sci Rev 212:743-810

Plank T, Langmuir AH (1992) Effects of melting regime on the composition of the oceanic crust. J Geophys Res 97:19749-19770

Price MG, Davies JH, Panton J (2019) Controls on the deep-water cycle within three-dimensional mantle convection models. Geochem Geophys Geosyst 20

Revenaugh J, Sipkin SA (1994) Seismic evidence for silicate melt atop the 410-km mantle discontinuity. Nature 369:474-476

Ribe NM (1985a) The deformation and compaction of partial molten zones. Geophys J Roy Astron Soc 83:487-501

Ribe NM (1985b) The generation and compaction of partial melts in the earth's mantle. Earth Planet Sci Lett 73:361-376

Richard G, Monnereau M, Ingrin J (2002) Is the transition zone an empty water reservoir? Inference from numerical model of mantle dynamics. Earth Planet Sci Lett 205:37-51

Rogers LA, Bodenheimer P, Lissauer JJ, Seager S (2011) Formation and structure of low-density exo-planets. Astrophysical J 738:59-75

Rubey WW (1951) Geologic history of sea water, an attempt to state the problem. Geol Soc Am Bull 62:1111-1148

Rüpke LH, Phipps Morgan J, Dixon JE (2006) Implications of subduction rehydration for Earth's deep water cycle. In: Jacobsen SD, Lee Svd (eds) Earth's Deep Water Cycle. American Geophysical Union, Washington DC, pp 263-276

Rüpke LH, Phipps Morgan J, Hort M, Connolly JAD (2004) Serpentine and the subduction zone water cycle. Earth Planet Sci Lett 223:17-34

Sakamaki T (2017) Density of hydrous magma. Chem Geol 475:135-139

Sanloup C, Drewitt JWE, Konopková Z, Dalladay-Simpson P, Morton DM, Rai N, van Westrenen W, Morgenroth W (2013) Structural change in molten basalt at deep mantle conditions. Nature 503:104-107

Schaefer L, Sasselov D (2015) The persistence of ceans on Earth-like planets: Insights from the deep-water cycle. The Astrophysical Journal 801, 40. https://doi.org/10.1088/0004-637X/801/1/40

Schmandt B, Jacobsen SD, Becker TW, Liu Z, Dueker KG (2014) Dehydration melting at the top of the lower mantle. Science 344:1265-1268

Sengör AMC, Burke K (1978) Relative timing of rifting and volcanismon Earth and its tectonic implications. Geophys Res Lett 5:419-421

Sobolev AV, Asanov EV, Gurenko AA, Arndt NT, Batanova VG, Portnyagin MV, Garbe-Schönberg D, Wilson AH, Byerly GR (2019) Deep hydrous mantle 
reservoir provides evidence for crustal recycling before 3.3 billion years ago. Nature 571:555-559

Song T-RA, Helmberger DV, Grand SP (2004) Low-velocity zone atop the 410-km seismic discontinuity in the northwestern United States. Nature 427:530-533

Spetzler HA, Anderson DL (1968) The effect of temperature and partial melting on velocity and attenuation in a simple binary system. J Geophys Res 73: 6051-6060

Spohn T, Sohl F, Breuer D (1998) Mars. Astronomical Astrophysical Rev 8:181-235

Stocker RL, Gordon RB (1975) Velocity and internal friction in partial melts. J Geophys Res 80:4828-4836

Stolper EM, Walker D, Hager BH, Hays JF (1981) Melt segregation from partially molten source regions: the importance of melt density and source region size. J Geophys Res 86:6261-6271

Suetsugu D, Inoue T, Yamada A, Zhao D, Obayashi M (2006) Towards mapping three-dimensional distribution of water in the transition zone from P-wave velocity tomography and 660-km discontinuity depths. In: Jacobsen SD, Lee Svd (eds) Earth's Deep Water Cycle. American Geophysical Union, Washington DC, pp 237-249

Takei $Y$ (2002) Effect of pore geometry on Vp/Ns: from equilibrium geometry to crack. J Geophys Res 107. https://doi.org/10.1029/2001JB000522

Tao K, Grand SP, Niu F (2018) Seismic structure of the upper mantle beneath eastern Asia from full waveform seismic tomography. Geochem Geophys Geosyst 19:2732-2763

Tauzin B, Debayle E, Wittingger G (2010) Seismic evidence for a global lowvelocity layer within the Earth's upper mantle. Nat Geosci 3:718-721

Torsvik TH, Cocks LRM (2019) The integration of paleomagnetism, the geological record and mantle tomography in the location of ancient continents. Geol Mag 156:242-260

Tschauner O, Huang S, Greenberg E, Prakapenka VB, Ma C, Rossman GR, Shen AH, Zhang D, Newville M, Lanzirotti A, Tait K (2018) Ice-VII inclusions in diamonds: Evidence for aqueous fluid in Earth's deep mantle. Science 359:1136-1139

van Keken PE, Hacker BR, Syracuse EM, Abers GA (2011) Subduction factory 4: Depth-dependent flux of $\mathrm{H} 2 \mathrm{O}$ from subducting slabs worldwide. J Geophys Res 116. https://doi.org/10.1029/2010JB007922

van Keken PE, Karato S, Yuen DA (1996) Rheological control of oceanic crust separation in the transition zone. Geophys Res Lett 23:1821-1824

Vinnik L, Farra V (2007) Low S velocity atop the 410-km discontinuity and mantle dynamics. Earth Planet Sci Lett 262:398-412

Wang W, Walter MJ, Peng Y, Redfern S, Wu Z (2019a) Constraining olivine abundance and water content of the mantle at the 410-km discontinuity from the elasticity of olivine and wadsleyite. Earth Planet Sci Lett 519:1-11

Wang Y, Pavlis GL, Li M (2019b) Heterogeneous distribution of water in the mantle transition zone inferred from wavefield imaging. Earth Planet Sci Lett 505:42-50

Wei SS, Shearer PM (2017) A sporadic low-velocity layer atop the 410-km discontinuity beneath the Pacific Ocean. J Geophys Res 122:5144-5159

Wise DU (1972) Freeboard of continents through time. Geol Soc Am Mem 132: $87-100$

Wise DU (1974) Continental margins, freeboard and the volumes of continents and ocean through time. In: Burk CA, Drake CL (eds) Geology of Continental Margins. Springer, New York, pp 45-58

Xu Y, McCammon C, Poe BT (1998) Effect of alumina on the electrical conductivity of silicate perovskite. Science 282:922-924

Yang J, Faccenda M (2020) Intraplate volcanism originating from upwelling hydrous mantle transition zone. Nature 579:88-91

Yoshino T, Nishihara Y, Karato S (2007) Complete wetting of olivine grainboundaries by a hydrous melt near the mantle transition zone. Earth Planet Sci Lett 256:466-472

Yuen DA, Peltier WR (1980) Mantle plumes and the thermal stability of the D layer. Geophys Res Lett 7:625-628

Zhang F, Wu Q, Grand SP, Li Y, Gao M, Demberel S, Ulziibat M, Sukhbaatar U (2018) Seismic velocity variations beneath Mongolia: Evidence for upper mantle plumes? Earth Planet Sci Lett 459:406-416

Zhao D, Ohtani E (2009) Deep slab subduction and dehydration and their geodynamic consequences: Evidence from seismology and mineral physics. Gondw Res 16:401-413

Zhu H, Bozdag E, Duffy TS, Tromp J (2013) Seismic attenuation beneath Europe and North Atlantic: implications for water in the mantle. Earth Planet Sci Lett 381:1-11

\section{Publisher's Note}

Springer Nature remains neutral with regard to jurisdictional claims in published maps and institutional affiliations.

\section{Submit your manuscript to a SpringerOpen ${ }^{\circ}$ journal and benefit from:}

- Convenient online submission

- Rigorous peer review

- Open access: articles freely available online

- High visibility within the field

- Retaining the copyright to your article

Submit your next manuscript at $\boldsymbol{\nabla}$ springeropen.com 